\title{
A CONSULTATION ON EUROPE WIDE VIEWS ON SUSTAINABLE CONSUMPTION
}
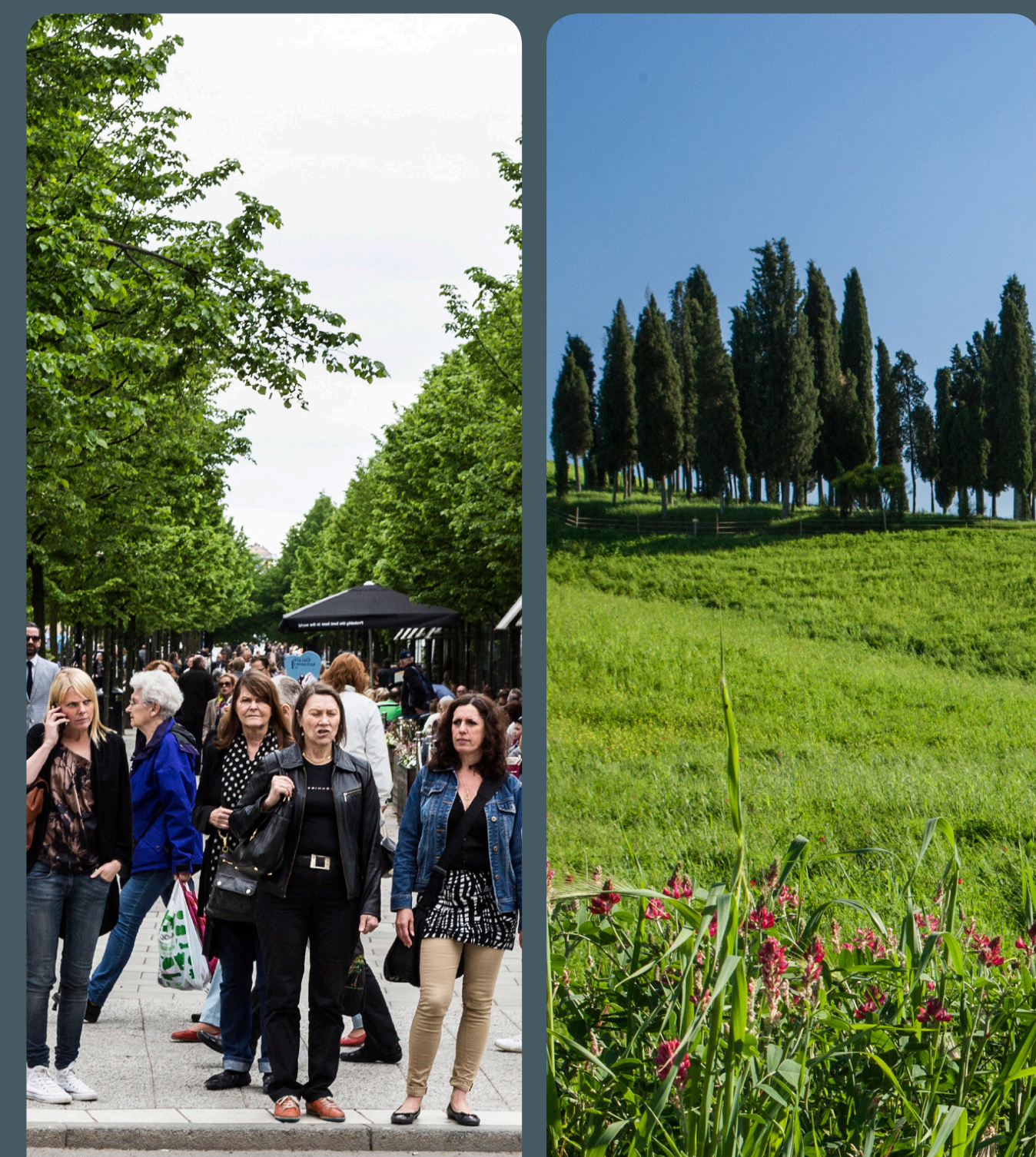

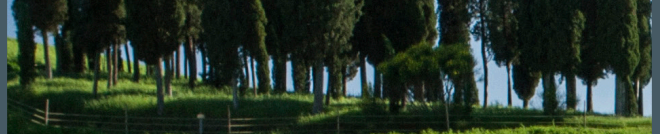

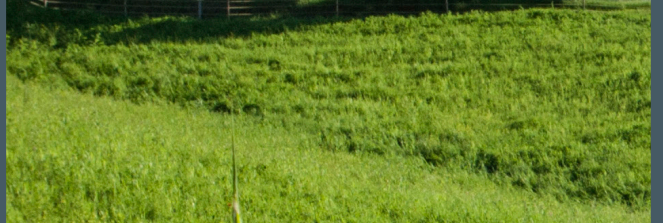
W. 2. She

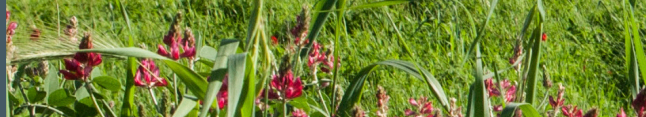
b.

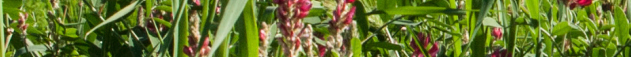

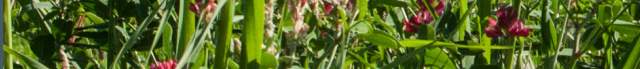

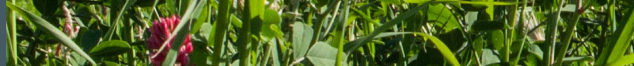
(8) (a)

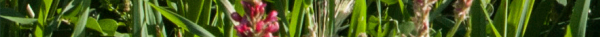

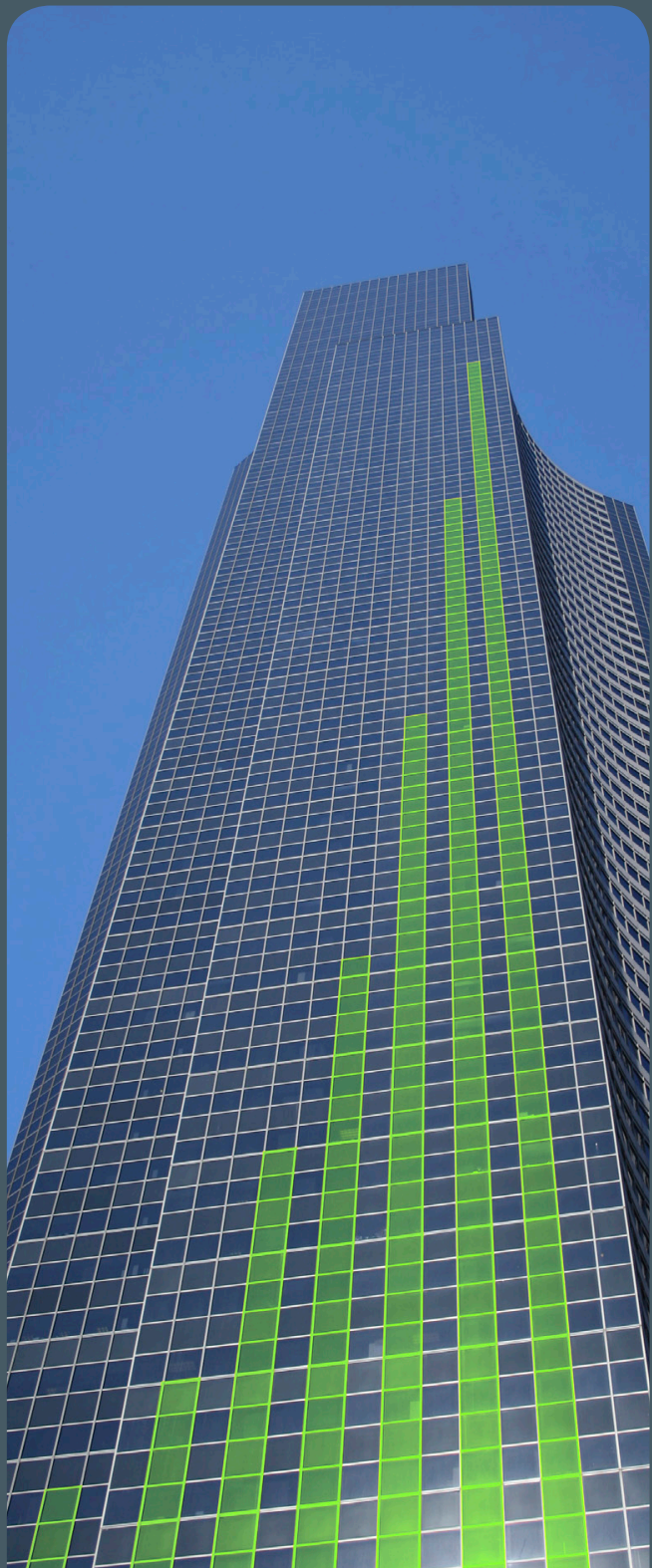




\section{INDEX}

INTRODUCTION

An introduction to the consultation

CHAPTER 1

Setting the Scene: Policy Making Instruments

\section{CHAPTER 2}

Shifting Consumption Towards Sustainability

NFOGRAPHIC

An infographic illustrating the concepts presented in this document

CHAPTER 3

Reducing Consumption

\section{CHAPTER 4}

Reducing Waste

\section{NOTES}

Space for your own notes

\section{APPENDIX}

References, citations, credits and legal information

\section{INTRODUCTION}
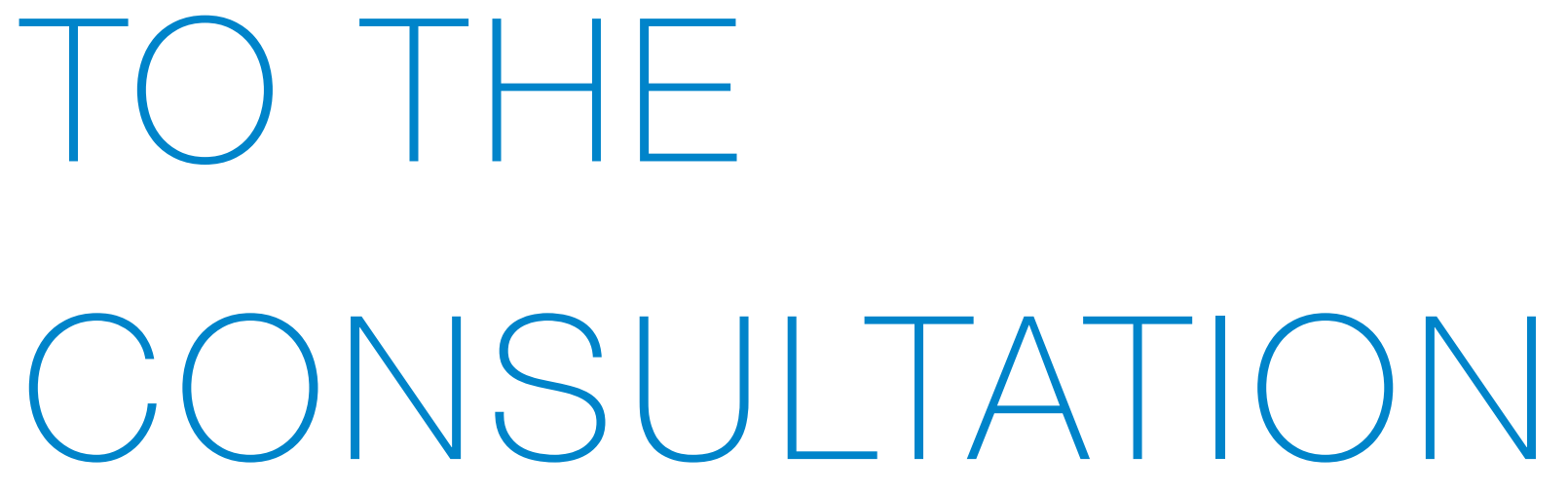

THANK YOU FOR AGREEING TO JOIN US ON 25 $5^{\text {TH }}$ OCTOBER

TO PROVIDE US WITH YOUR INSIGHTS AND OPINIONS. WE'RE VERY MUCH LOOKING FORWARD TO WHAT YOU HAVE TO SAY.

When we meet, we'll be looking at issues surrounding sustainable consumption and policy making.

The heart of the matter is this: in free markets, consumption choices are viewed as a private matter for individuals. Governments are generally hesitant to intervene too much in their citizens' private space. As a result, policies aimed at enhancing sustainable consumption tend to be focused on the production of goods and services, rather than on private consumption.

We would like to have a discussion with you about broadening the policy making surrounding sustainable consumption to include measures aimed at private citizens. We also want to get your views on the different roles that citizens could play in increasing sustainability in society.
WHAT IS SUSTAINABILITY?

Let's start by outlining what sustainability is.

One of the most common definitions of sustainable development is that coined by the Brundtland Commission". It says that sustainable development is "development that meets the needs of the present without compromising the ability of future generations to meet their own needs".

This definition has been criticised for placing an emphasis on development. More recent thinking has broadend the scope of sustainability to include social, environmental and economic sustainability ${ }^{2}$. In other words, we need to address sustainability from the perspective of people, planet and profit. 
WHAT IS SUSTAINABLE CONSUMPTION?

At the Norwegian Ministry of Environment, Oslo Symposium, 1994, sustainable consumption was defined as: "The use of services and related products, which respond to basic needs and bring a better quality of life while minimising the use of natural resources and toxic materials as well as the emissions of waste and pollutants over the life cycle of the service or product so as not to jeopardise the needs of future generations."

This is still one of the most useful definitions of sustainable consumption in use today and will serve as the basis for our discussions.

\section{WHY SUSTAINABLE CONSUMPTION IS} IMPORTANT

As it stands, the Earth's resources will not be able to support the current level of human production and consumption indefinitely. If current consumption patterns continue, by 2030 , we would need another planet to keep up ${ }^{3}$.

Moreover, human economic activity impact our natural environment. It contributes to globa warming, creates pollution and changes landscapes. We create fields, divert rivers, erect dams, build roads, construct factories, develop ports, and more - all to support the production and movement of goods.
The effects aren't just felt locally. According to the European Commission, "The impacts of consumption in the EU are felt globally, as the EU is dependent on the imports of energy and natural resources. Furthermore, an increasing proportion of products consumed in Europe are produced in other parts of the world." 4

Moreover, large parts of Asia and Africa are behind Europe in terms of their economic development. One of the biggest challenges for sustainability is the expected economic growth and increase in population in these regions.

All of this presents challenges if future generations are to have a good standard of living. Changes will be needed in order to balan people, planet and profit in a way that is effective and fair for all.

CHANGE THROUGH POLICY MAKING Policymakers in Europe are actively looking at solutions targeted at production as well as consumption. There are stakeholders everywhere, all of whom can influence the policy making process: policymakers themselves, politicians, interest groups, lobbyists, the media, industry bodies, trade unions, non-governmental organisations - the list goes on. Some of these have a louder voice than others. Some are given more airtime. Some are more effective at getting what

\section{WHAT IS PACITA?}

PACITA is a four-year EU-funded project that stands for Parliaments and Civil Society in Technology Assessment. It is aimed at improving policy making processes concerning issues relating to science, technology and innovation.

PACITA works to enhance the foundations of policy making by improving the knowledge base on which those policies are based. It does this by engaging interactively with a range of people and organisations. By doing so, it aims to uncover relevant knowledge, experience and expertise that may otherwise be overlooked in policy making.

You are participating in Europe Wide Views on Sustainable Consumption, a PACITA research project. It involves citizens from Austria, Belgium, Bulgaria, Czech Republic, Denmark, Hungary, Ireland, Lithuania, The Netherlands, Portugal and Spain. This is one of a number of projects being conducted under the PACITA banner.

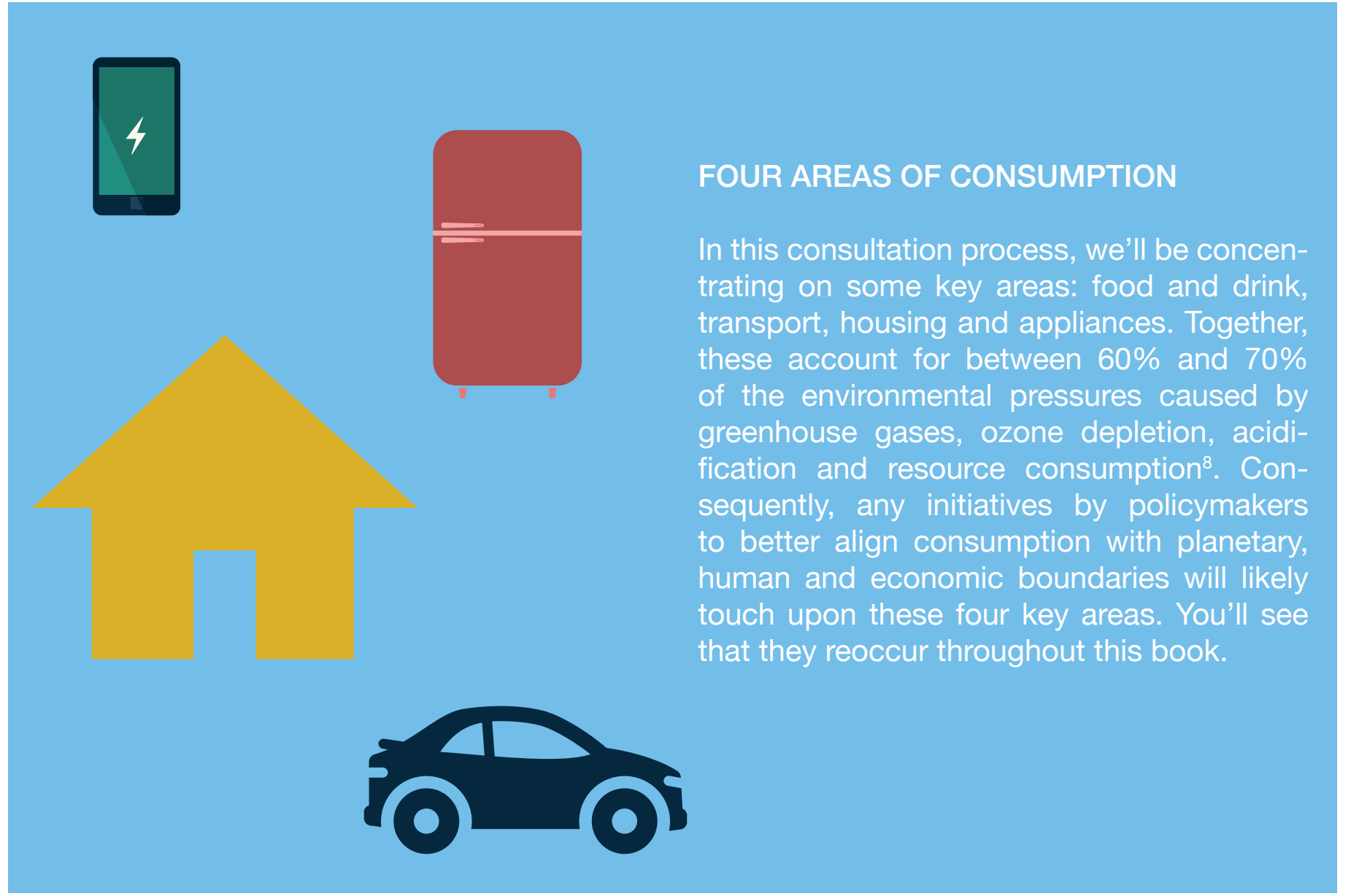

they want.

The PACITA project is curious to hear from one set of stakeholders in particular: regular citizens. As part of the consultation you're participating in, we'll hear how citizens from 11 different European countries view policies around sustainable consumption. We're curious to find out what types of instruments citizens think policymakers should use, how intrusive or prescriptive measures should be, and at what levels policies should be made. In short: if change is what's required, who do citizens think should take control of that process and how should they go about it?

Some changes require fundamental choices and involve difficult trade-offs. Other changes are incremental and come about without anyone really noticing. Moreover, a single change can solve more than one problem. For instance, reducing pollution creates associated jobs, improves the environment and benefits human health. Such instances are the ideal. They don't always happen. Sometimes, tackling a socia sustainability issue will come at the expense of economic or environmental concerns. Finding solutions in one space that don't adversely affect either or both of the others is difficult. Let alone finding solutions that enhance people, profit and planet equally.

\section{THREE POSSIBLE PATHS}

There is no single solution to achieving more sustainable consumption. In this booklet, and in our consultation with you in general, we will touch upon three possibilities, none of which are mutually exclusive.

The first is to move towards more sustainable consumption patterns. This encourages a balance between what and how people consume and the pressures consumption places on the planet's resources, economies and societies.

The second route we'll look at is reducing the evel of consumption. This can be brought about in part by changing attitudes towards consumption and in part by changing production and manufacturing processes.

Finally, social, environmental and economic 
pressures caused by consumption can also be reduced by cutting back on the amount of waste consumption creates.

From a policymaker's point of view, the best solutions don't entail any trade-offs. Ideally, a policy leads to improvement without removing choice or adversely affecting other areas. That's not always possible, however.

\section{THE EU AND ITS AMBITIONS}

The EU is looking at sustainability in a number of ways. Resource and energy efficiency have both featured heavily in its discussions. Most recently, it has started to look at the notion of a circular economy - an economy that produces virtually no waste.

A key initiative at the moment is Europe $2020^{5}$ the EU's growth strategy until the end of the decade. According to José Manuel Barroso, outgoing President of the European Commission, Europe 2020 aims to achieve "a smart, sustainable and inclusive economy, with high levels of employment, productivity and social cohesion".

Europe 2020 steers a number of other initiatives. One is The Roadmap to a Resource Efficient Europe, which outlines how Europe's economy could be transformed into a sustainable one by 2050 .

The Roadmap is ambitious in its vision: "By 2050 the EU's economy has grown in a way that respects resource constraints and planetary boundaries, thus contributing to global economic transformation. Our economy is compet itive, inclusive and provides a high standard of living with much lower environmental impacts. All resources are sustainably managed, from raw materials to energy, water, air, land and soil. Climate change milestones have been reached while biodiversity and the ecosystem services it underpins have been protected, valued and substantially restored." 6

Another initiative driven by Europe 2020 is the Action Plan for Sustainable Consumption and Production (SCP) and Sustainable Industrial Policy $(\mathrm{SIP})^{7}$. This aims to ensure a leading role for the EU in terms of environmental perfor- mance. At its heart is a framework to improve the energy and environmental performance of products and foster their uptake by consumers. The outcome of these initiatives could be a society very different from today's.

HOW THIS BOOKLET IS STRUCTURED

This booklet has been split into four parts. Each one mirrors one of the sessions that you will participate in on the citizen consultation day.

Chapter 1 provides you with background information regarding sustainable consumption and policy making.

Chapter 2 looks at shifting towards sustainable consumption.

Chapter 3 will cover issues surrounding reducing consumption.

Chapter 4 is about reducing waste and the perspective of a so-called circular economy.

At the end of the book, there is an appendix with a list of the source material used in compiling this booklet.

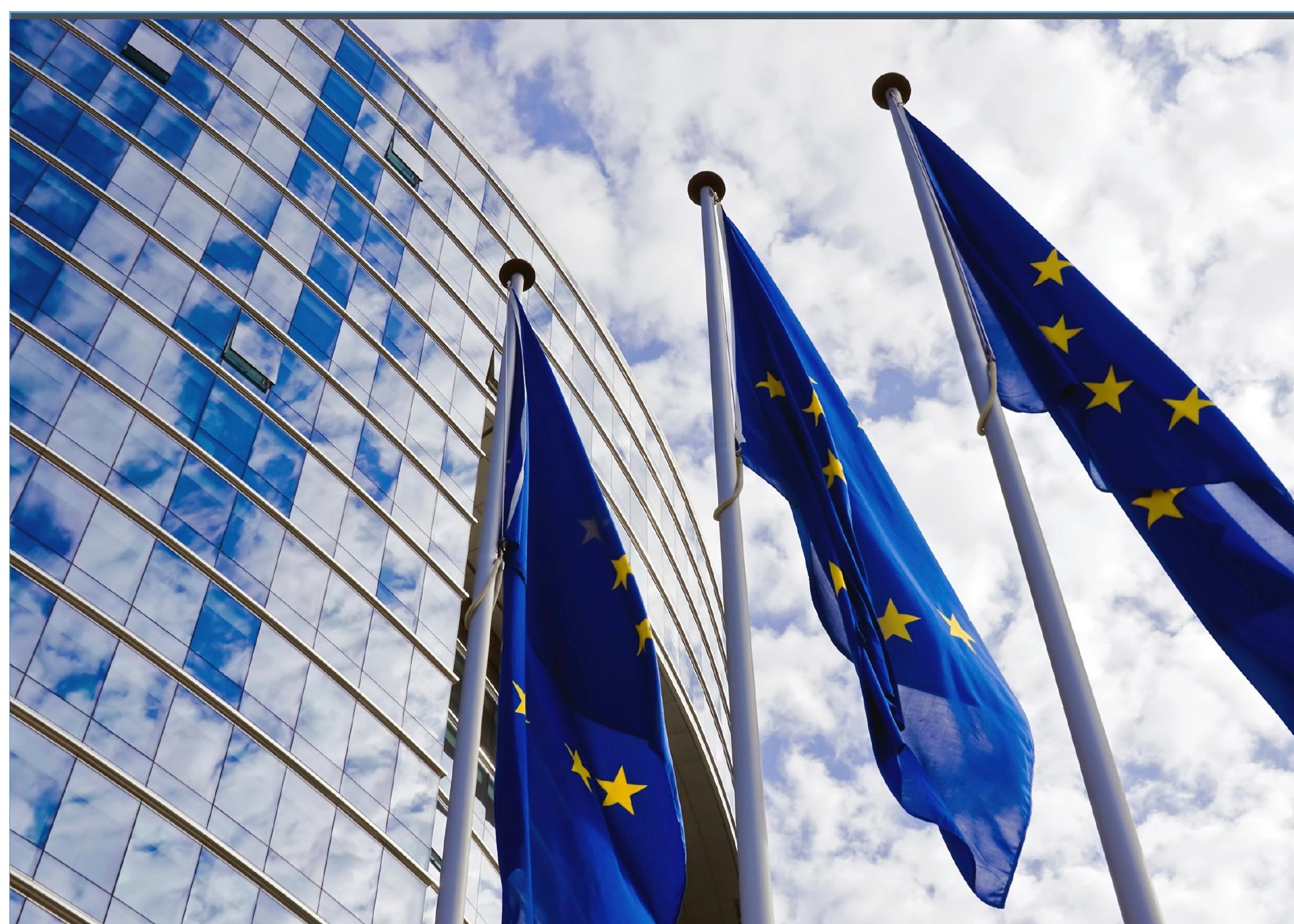



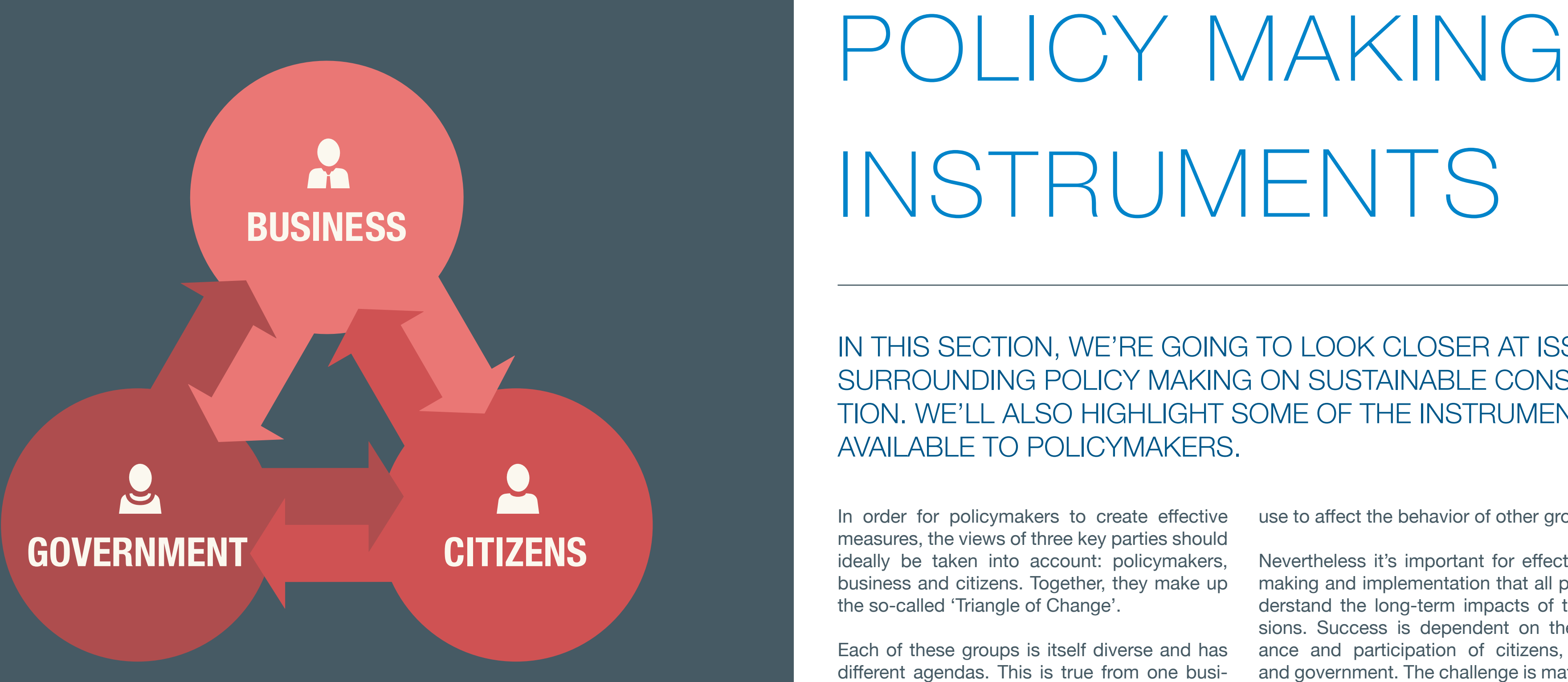

TRIANGLE OF CHANGE

\section{SETTING THE} SCENE:

IN THIS SECTION, WE'RE GOING TO LOOK CLOSER AT ISSUES SURROUNDING POLICY MAKING ON SUSTAINABLE CONSUMPTION. WE'LL ALSO HIGHLIGHT SOME OF THE INSTRUMENTS AVAILABLE TO POLICYMAKERS.

In order for policymakers to create effective measures, the views of three key parties should ideally be taken into account: policymakers, business and citizens. Together, they make up the so-called 'Triangle of Change'.

Each of these groups is itself diverse and has different agendas. This is true from one business to another, for different groups of citizens and for policymakers, who may represent different constituents or have varying degrees of power.

use to affect the behavior of other groups.

Nevertheless it's important for effective policy making and implementation that all parties understand the long-term impacts of their decisions. Success is dependent on the acceptance and participation of citizens, business and government. The challenge is matching the agendas of such diverse groups. How should that be done?

Creating policy across a political union as socially, economically and culturally diverse as the EU isn't simple. Let's consider just one of the 


\section{GREEN PROCUREMENT}

In many ways, the price that consumers pay for goods and services doesn't reflect all of the costs involved. Prices rarely include the cost of replenishing the resources used or managing side effects such as pollution, for instance.

If the broader aspects associated with the extraction of raw materials, transport, production, use and disposal were included in the prices of products, there would be more transparency about their true cost to society.

Such transparency would enable practices such as green procurement. This is purchasing that emphasises environmental considerations at all stages of the procurement process.

three groups mentioned above: citizens.

The EU's citizens aren't all the same. They live in different places, have different access to resources and products, live by different cultural rules and under different economic circumstances. Their historic and social roots vary. And each person sees sustainable consumption, or the need for it, differently. All of this impacts on what, how, how much and when they consume.

Even if they did all share the same background and opinions, they would be different in how they acted upon them. Decisions about personal consumption are often governed by trade-offs people feel they have to make. Some decisions are acceptable to some people, but not to others.

Take the use of the car, for instance. Private car use places more demands on resources than public transport alternatives: it requires more infrastructure, more land and burns considerable oil resources. Yet at the same time, it is convenient, provides freedom of movement, helps us transport our children and our shopping, and saves time. In remote areas, it is often the only means of transport. How should policies affecting car use balance sometimes conflicting needs? And what role could technological advances play in reducing the impact of private car ownership?

The car is a good example of another aspect of consumption. Sometimes people aren't fuly conscious of the consumption choices they make. The car is a commonly accepted and popular means of transport in many EU countries. Citizens there take private car ownership for granted. For citizens in other countries, by contrast, the bicycle is the most obvious choice of transport Transport habits differ across the EU from country to country, and within countries as well.

And it's not just today's citizens who are affected by today's policies. What is decided today affects future generations too. How can we best take this into consideration?

CONSUMPTION POLICIES ARE

FAR-REACHING

Consumption is at the core of many of our daily activities. It drives our economies, affects our relationship with the environment, and often defines key aspects of our societies and cultures. Because of the interwoven nature of consumption, policy measures regarding consumption impact a broader range of fundamental issues, including climate change, food supply, technology development, human rights, justice and social equality - to name only a few. A tweak to one aspect of our consumption patterns can generate ripple effects in many other parts of society.

As a result, policymakers have to consider what impact their decisions will have elsewhere. Some of these might create resistance.

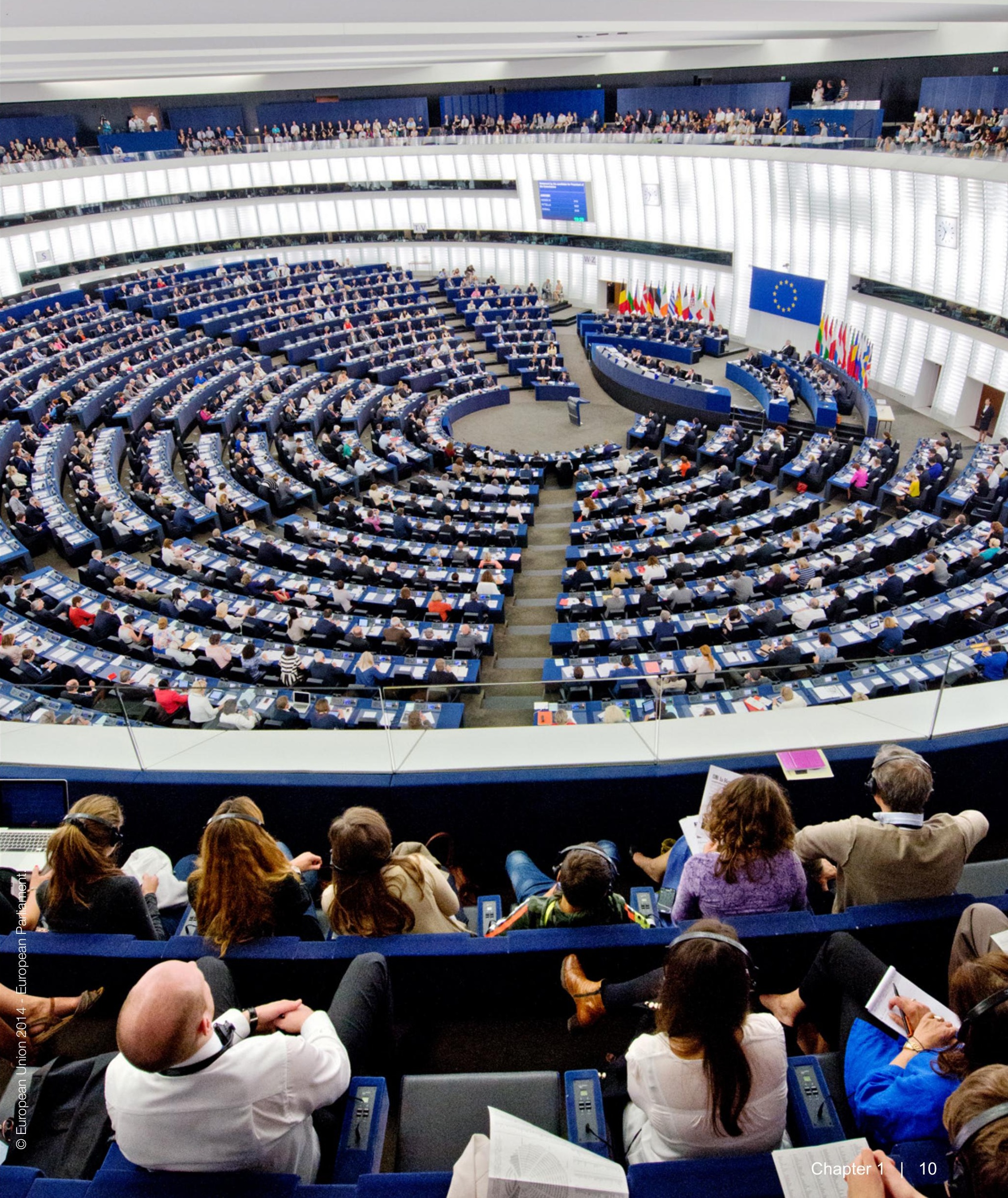





\section{REGULATION}

Regulation is prescriptive and carries with it the threat of sanctions for non-compliance. Bans, mandatory standards, permits, planning permission - these are all examples of regulator instruments. Policymakers can also use regulation to lead by example. For instance, they can oblige public bodies to adhere to social responsibility rules or implement green public procurement schemes.

Regulation can be very successful in chang ing consumption behaviour. Regulation also requires enforcement, which places additiona administrative burdens on local and nationa governments.

To be effective, regulation needs to keep up with changes and innovation. Technology often moves more quickly than legislators are able to.

In some instances, regulation reduces the choices available to citizens by taking products or services off the market. This means that policymakers need to strike a balance between what is needed and what citizens will stand for The European Economic and Social Committee (EESC) has highlighted concerns among citizens that certain areas are over-regulated. The phasing out of incandescent light bulbs in favour of more energy efficient alternatives is one example where throughout the EU citizens voiced their discontent.

In the main, regulation is aimed at manufacturers and public bodies, less so at consumers directly.

FINANCIAL INSTRUMENTS

The notion of financial incentives or disincentives isn't new for policymakers. They tax the behaviours they want to reduce and subsidise the ones they want to stimulate. People (both citizens and business people) are susceptible to what goes on in their wallets and respond accordingly.

According to the Organisation for Economic Cooperation and Development (OECD), financial measures work best when they are bold and significant, and when they clearly close the price gap between sustainable products and less sustainable ones. Small financial incentives or disincentives register little effect.

In addition to taxes and subsidies, policymakers can turn to loan schemes for sustainable goods, bonus schemes to encourage the purchase of sustainable products, discount coupons for certain products, and so on.

If policymakers choose to use taxation to bring about change, they need to be careful that they don't disproportionately affect lower- and middle-income households. Doing so can increase social inequality.

One suggestion currently popular at various levels within the EU is that taxation should be shifted from labour-related taxes (such as income tax and taxes levied on employers when they hire someone) to consumption taxes such as sales taxes. The EU Commission is keen to see governments move beyond emphasizing raising revenue towards using fiscal measures to stimulate sustainable behaviour.

\section{SUGGESTION}

Policymakers can try to effect change by making certain choices more appealing to consumers - often without the latter realising what's happening.

Some seek to influence by using role models and celebrities. This makes the suggested behaviour appealing and fashionable. On the flip side, there is a risk of consumers returning to previous habits once the novelty has worn off.

Other initiatives rely on emotion. Guilt is a powerful driver of behavioural change. However, it has been suggested by psychologists that relying too heavily on creating a sense of guilt among a target audience can result in them switching off.

Subtle measures have been used in some places to modify behaviour. Examples are the provision of smaller plates to encourage smaller portion sizes, withholding plastic bags at checkouts, giving pre-selected default choices during a purchasing process, or appealing waste bins in to encourage their use. Cultural context may have an impact on how effec- tive these measures are across the EU. Equally, familiarity may reduce their effectiveness aft while as well.

Lastly, there are initiatives that are designed to encourage collaborative consumption: use of products among individuals rather than singleperson ownership. This is also known as the sharing economy - in which consumers actively exchange tools, goods and services. These initiatives tend to be generated at grassroots leve where people seek to influence each other, and it isn't yet well understood how regulation from above could (or should) impact such movements.

SOME OR ALL OF THE ABOVE

Most of the time, policymakers mix and match their initiatives, drawing from some or all of the above.

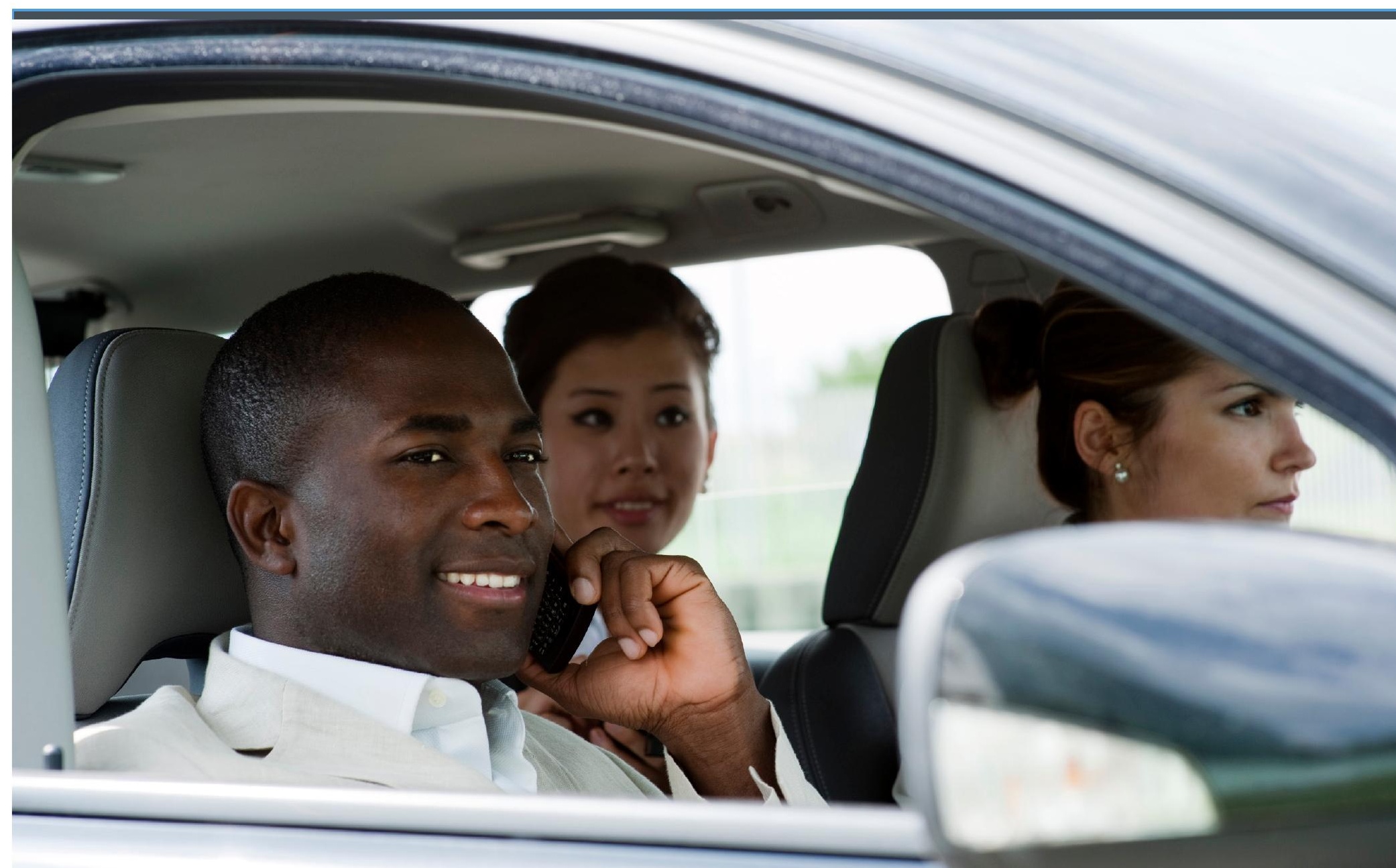




\section{SHIFTING

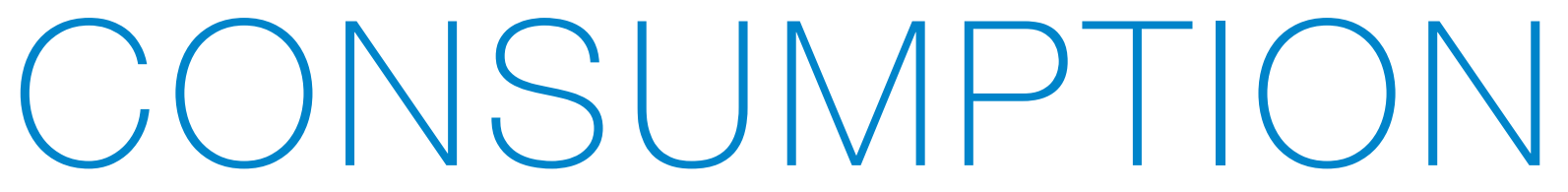 \\ TOWARDS \\ SUSTAINABILITY}

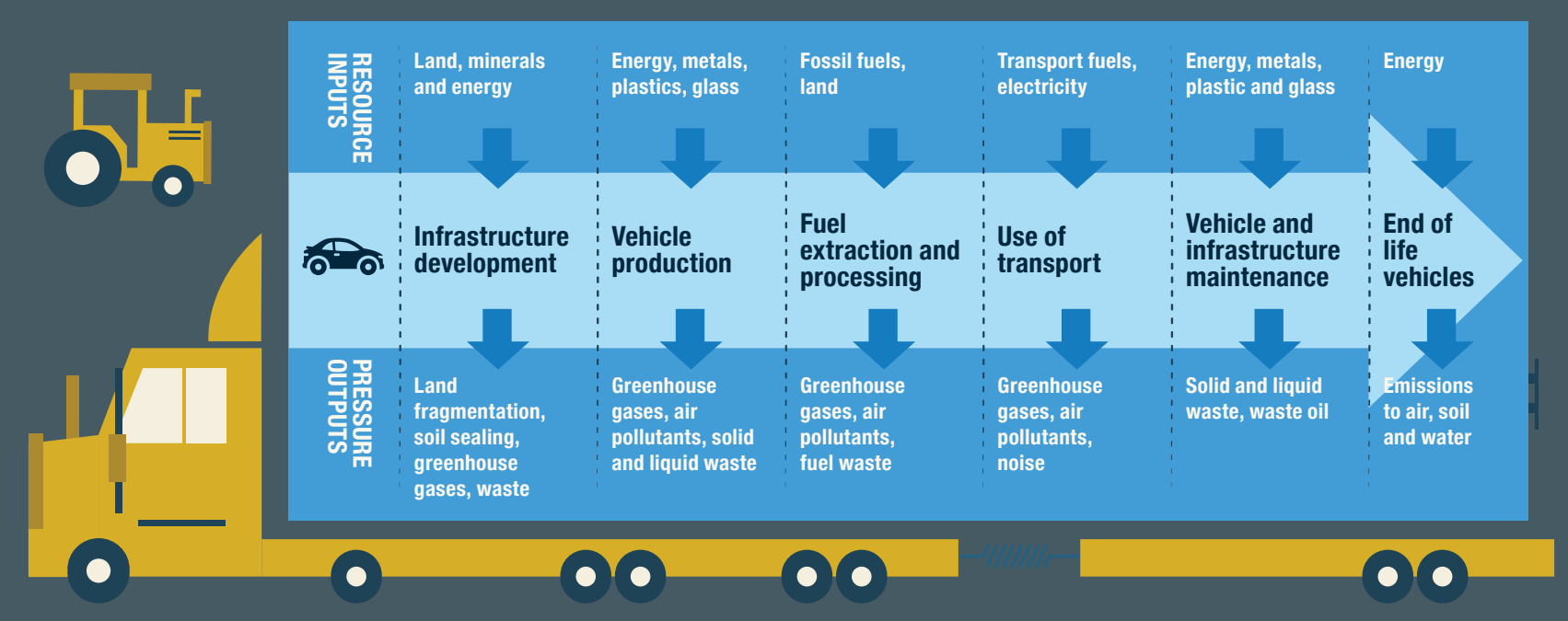

TRANSPORT
IF THE EU IS TO BECOME A MORE SUSTAINABLE SOCIETY, IT WILL NEED TO CHANGE ITS CONSUMPTION PATTERNS. ONE OPTION IS TO MOVE TOWARDS MORE SUSTAINABLE PRODUCTS AND SERVICES. IN THIS CHAPTER, WE'LL LOOK AT SOME OF THE WAYS THIS COULD BE DONE.

Sustainable consumption is consumption that can be carried on indefinitely. It doesn't exhaust resources. Nor does it create social or economic imbalances.

Choosing sustainable consumption doesn't necessarily entail less consumption (the topic of the next chapter). Instead, it emphasises transitioning to sustainable alternatives to current products and services. For instance, a shift to renewable energy sources doesn't lead to lower energy consumption in general. It merely changes the source of the energy.

The issue of shifting consumption raises questions about the relationship between policymakers and citizens. To what extent should policymakers take the lead? How much latitude should citizens be given to make their own choices? And what role is there for them 
in bringing about changes in consumption patterns?

Answering these questions isn't easy. Yet to be effective, policymakers must find out what consumers genuinely think. They must build policies that not only connect with that sentiment but engage with what citizens are willing to do as well. Not least because there is a recognised gap between what consumers genuinely fee (and say) and what they actually can and will do.

CITIZENS VARY

Add to this the fact that citizens aren't all the same. Rather than being a homogenous group consumers are disparate individuals with different levels of willingness and ability to tailor their choices and actions towards more sustainable consumption patterns.

Some people are interested in sustainability. Others are less so, or they have other priorities. Maybe their disinterest stems from a lack of relevant information or a lack of time to find out more.

Not everyone is in the same position to effect change. The higher up someone is in a hierarchy, the more influence they have. For instance, lower level employees have less influence on company consumption policies than executives do.

Life choice or social circumstances also have an impact. For example, homeowners can do more about home-related consumption than those living in rental properties. They can decide to install more efficient boilers or heating systems, replace old windows with doubleglazed alternatives, and so on. By comparison, people in rental properties pay the energy bills but often have little say over the heating system that is installed.

The same applies to people's economic situation. If making products more sustainable increases their cost, not everyone will be in a position to buy them.

WHAT SHOULD CITIZENS DO?

The role of citizens in moving society towards a more sustainable model is an interesting one. s it their place to bring about such a change on their own? If so, what avenues are open to them?

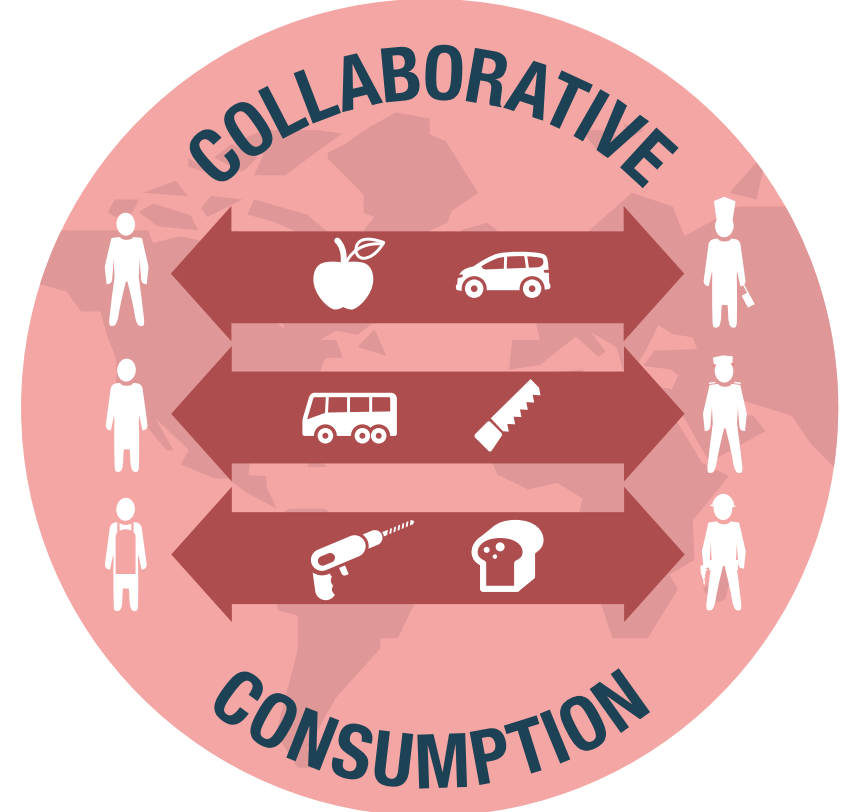

The most obvious route to bringing about more sustainable consumption is through their purchasing behaviour. They can buy the products they approve of, shunning those they don't.

The impact of the individual consumer's purchasing choice is perhaps small, but collectively consumers pack a punch. For instance, collective purchasing or consumption action at a local level can aid sustainability - bartering, collaborative gardening schemes, renewable energy cooperatives are all examples.

Moreover, by behaving more sustainably themselves, individual citizens and collectives can set a persuasive example for others to follow.

Citizens can also make their views felt at the ballot box to influence those who are in a position to bring about change. Outside of election years, they can petition legislators directly, using a range of mechanisms from letter writing to street demonstrations.

TRANSPORT AND SUSTAINABILITY

One of the areas of modern consumption that is at odds with sustainability at the moment is transport. In particular private car use and air travel.

According to the latest predictions by the Eu-

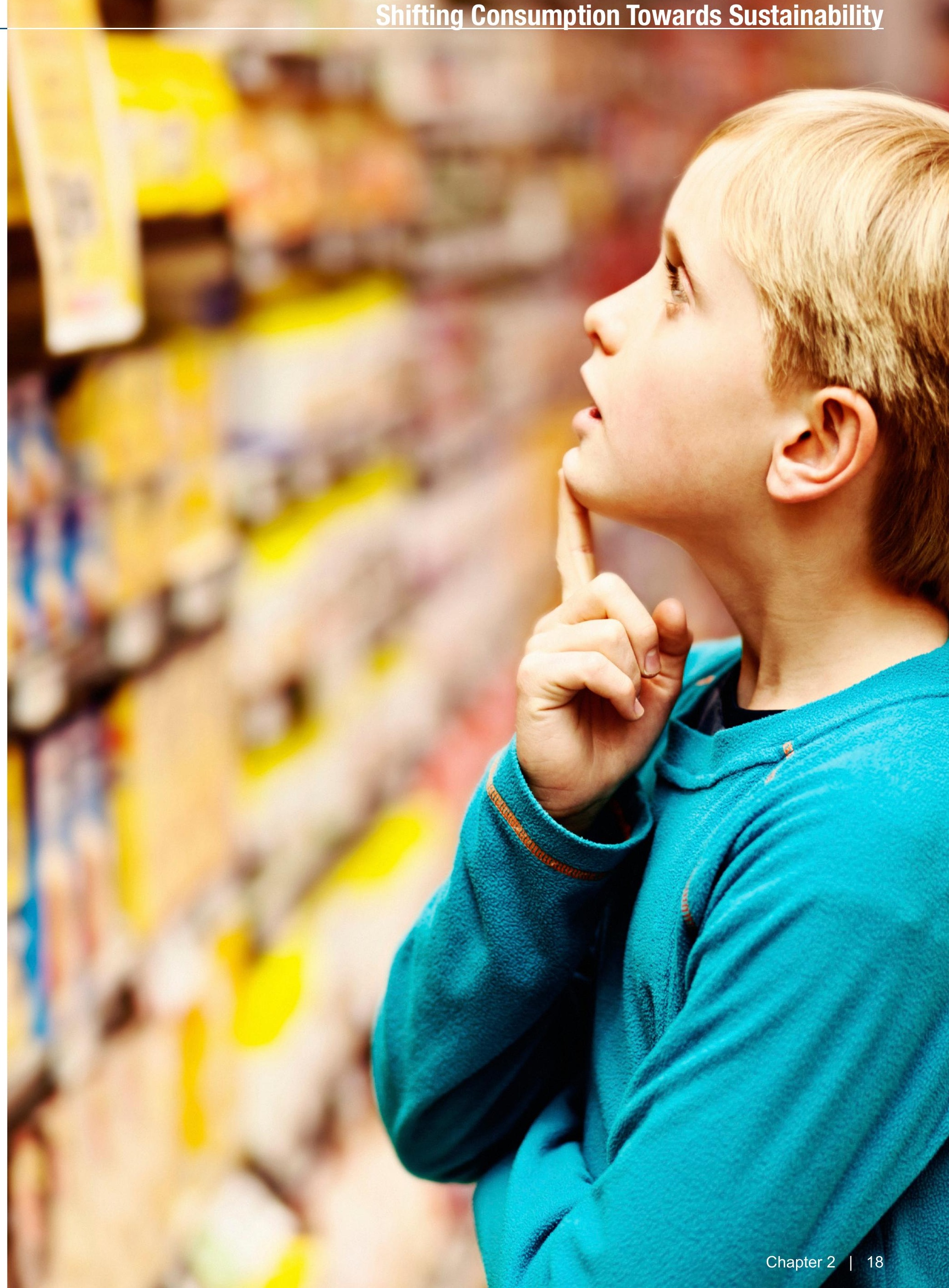


by 2050 , demand for pas senger transport will have increased by around $40 \%$ compared with 2010. Demand for freigh transport will have risen by around $54 \%{ }^{10}$

Despite a small decrease, the forecast shows that cars will still account for over two thirds of passenger transport in 2050. Is that something policymakers should be looking to reduce? After all, doing so would affect the individual's choice and options.

If policymakers are going to steer societies towards alternatives, there are several ways in which they could influence transport behaviours.

The first is to provide financial incentives or disincentives. For instance, tax incentives for cycle-to-work schemes or carpooling. Financial support for the purchase of low-emission vehicles is another option. Governments could introduce higher fuel duties or place levy tolls on roads or in city centres.

A second option is to favour collective transport solutions over individual cars when infrastructure is being planned. That isn't easy. Car ownership is an especially delicate topic in debates about sustainable consumption. For some, the car is a symbol of individual freedom. For others, it is vital to their mobility in areas where public transport is underdeveloped.

In many cases, private road transport has become ingrained in our societies. Consequently, cultural biases towards roads mean that much land planning is done from the basis of giving private cars preferential treatment. Changing that will require a huge shift in people's attitudes towards private car ownership in some countries.

PROVIDING EFFECTIVE INFORMATION

As we saw in the previous section, one of the tools that policymakers have is providing information. It can be used to support decisions they make on behalf of citizens. It can also be used to help citizens make their own choices.

One of the most effective ways of providing citizens with information relating to consumer choice is labelling It is also one of the most difficult to get right. Done well, labels give citizens confidence and are an easy aid to consumption choices. Done badly, they can leave citizens wary or confused.

Car Use in the EU

Transport modes people use at least once a day

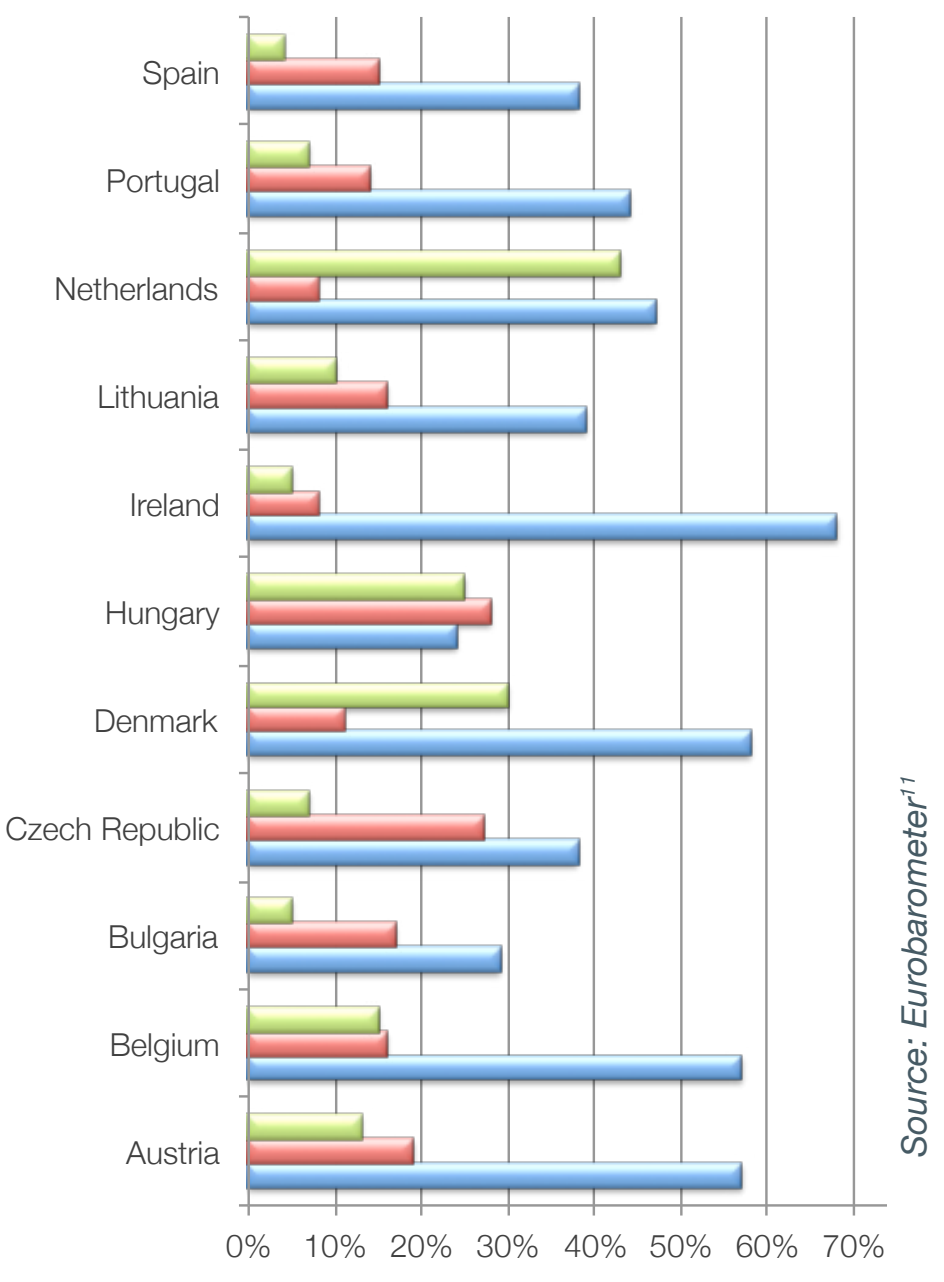

$\square$ Bicycle $\square$ Public Transport $\square$ a Car (driver or passanger)

For instance, labelling initiatives are popular but differ considerably in their scope: what products are eligible, what environmental and trading standards they adhere to, what impact they have, where geographically the impacts are felt, and so on.

Add to this that EU member states aren't all at the same point in terms of labelling and standards initiatives. Take the use of the word 'Organic' in the food sector, for instance. In some countries, its use is common. In others, it is a relatively new concept in consumer circles. The phrase may even relate to different things in different countries.

Chapter 2 | 20 


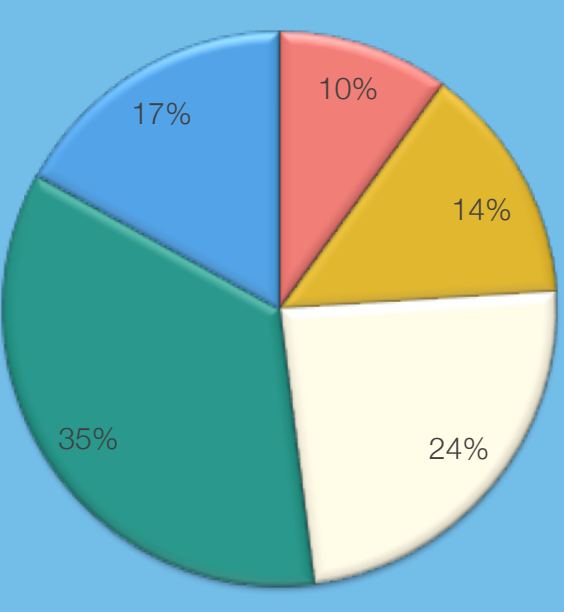

\section{THE EU'S ENERGY MIX}

Currently, the EU imports a large share of its energy needs. Dependency on overseas oil was in excess of $80 \%$ in 2011 , while reliance on imports for gas was over $60 \%$. Its dependency on imports is expected to increase. The European Commission expects reliance on imports of oil to exceed $90 \%$ by 2030. We'll be reliant on imports for $80 \%$ of our gas.

Set out in the pie chart is the overall make up of EU energy consumption as it was in 2011 .

『Renewables 『Nuclear $\square$ Gas $\square$ Oil $\square$ Solid Fuels

Source: European Commission

There is a role for legislators at EU level perhaps to bring about some standardization and simplification of labelling throughout the Union. An example of this is the EU Ecolabel, which started life as a designation for electronic goods. It's now being used across a much broader range of products, and it could be extended to cover services too.

\section{NEUTRAL POLICIES VS SETIING CHOICES} The efficient provision of accurate information makes decision-making easier for citizens. However, it can also leave plenty of wriggle room. For some, that's acceptable: it's up to the individual, organisation or country to use the information effectively. Others are less comfortable with this because it can lead to targets being missed.

The EU's energy targets are a good example. By 2020 , it would like to increase energy efficiency by $20 \%$, reduce greenhouse gas emissions by $20 \%$ and increase renewable energy consumption by $20 \%{ }^{12}$. Some countries are on track to achieve these targets. Others aren't.

One way for the EU to encourage the desired outcome could be for it to prescribe binding targets and ensure that it is able to hand out sanctions to those member states that fall short. Otherwise, it risks missing its goals of reduc ing the use of (and by association the reliance on) fossil fuels. However, some feel that such an approach doesn't make allowances for the their targe member states to choose one over the other. sources individual member states rely on?

TOP DOWN VS BOTTOM UP helping policymakers achieve their objectives.
Collaborative programmes can help communities do more with less. Technology is often at the nub of these developments, bringing people together more easily to hire, swap, trade, barter or share products on a scale we haven't seen previously Such initiatives reduce the pressure on resources by emphasizing durability and making products $g 0$ further and benefit a larger number of people, enhancing social equality.

People are also starting to work together to produce food. Throughout Europe there are examples of local residents collectively producing crops, fruit and meat on small pockets of land.

How policymakers should engage with collaborative consumption initiatives is a big question. As with any of the topics discussed in this booklet, the first question that needs to be asked is whether policymakers should seek to get involved in grassroots initiatives at all? If they do, how should they interact?

This links into the debate about how prescriptive the EU should be in terms of the technology choices made by member states to reach leaves countries free to choose which technology they implement. For instance, emissions reductions could be achieved both by nuclear and wind technology. Those who favour a technology-neutral stance are reluctant to oblige

In the future, EU policymakers could shift towards a less technology-neutral stance. They could start making clear technological choices in the energy sector, for instance, favouring certain solutions over others. However, there is little agreement among EU members themselves on this issue, or whether these policies should even be developed at EU level. Perhaps national governments are better placed to tackle energy issues, given the different mixes of energy

Debates around policy making tend to focus on the top-down nature of the process. Decisions made by governments are handed down to their citizens. What is often lost is the contribution that grassroots initiatives could and can have in

Where policymakers do get involved with community-based action, they have a wide range of measures at their disposal. For instance, one option is direct and indirect financial support, perhaps through government-citizen partnership programmes. Governments could facilitate the exchange of information regarding best practice, or provide logistical support. Maybe more responsibility could be delegated to local communities?

Whatever policymakers decide, it is clear that collaborative consumption programmes can play a role in creating sustainable societies if they manage to grow and adapt to the communities they are in.
ALTERNATIVE TYPES OF CONSUMPTION

Not only are European consumers aware of alternative types of consumption, they are actively considering how they might use them in future. Set out in the graph is the percentage of respondents to a recent survey who are considering a particular kind of alternative consumption.

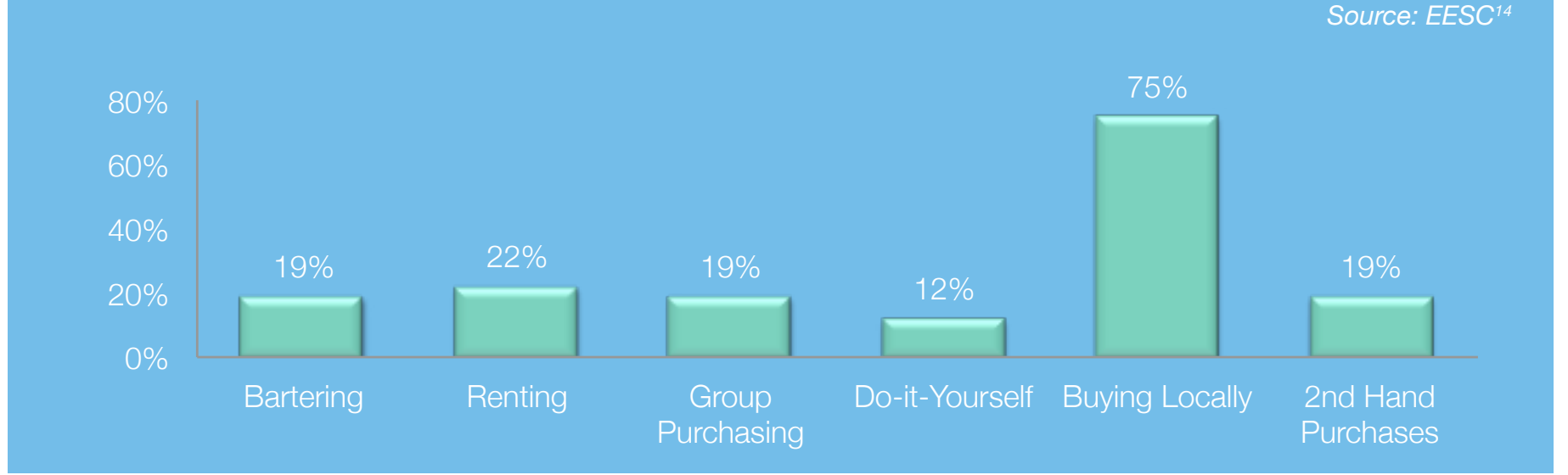

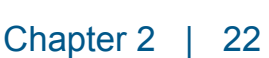


SUSTAINABLE CONSUMPTION

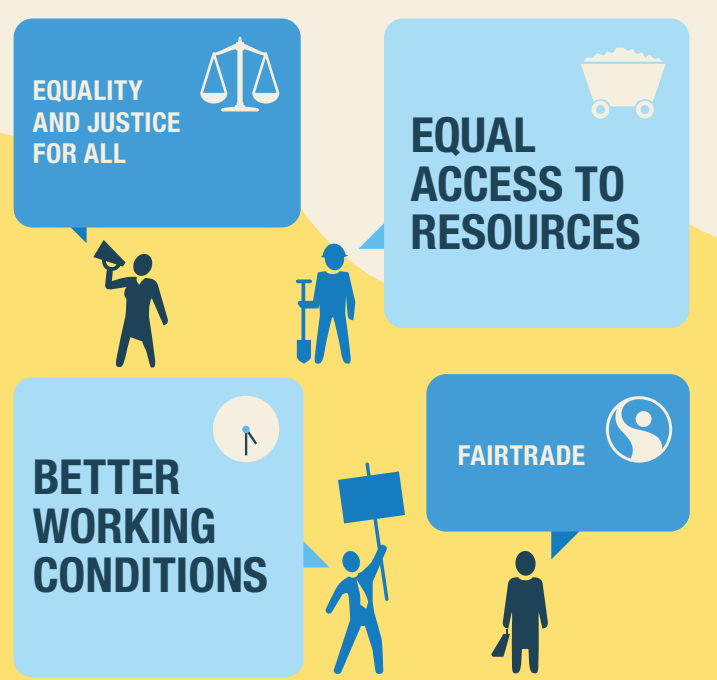

\section{CRITICAL}

MINERALS

THE EU IS DEPENDENT ON

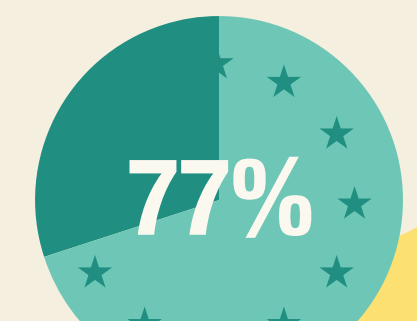

\begin{tabular}{ll|l|l}
$100 \%$ & $96 \%$ & $85 \%$ & $15 \%$
\end{tabular}

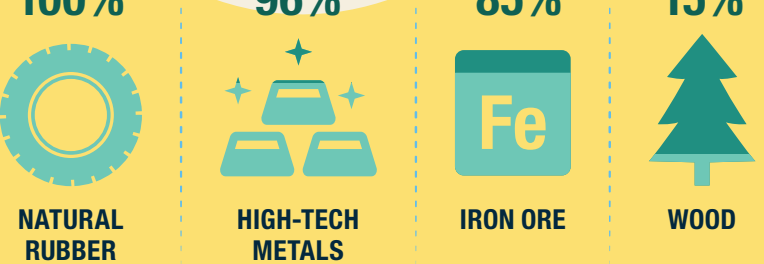

\begin{tabular}{c|c:c:c}
$\underset{\substack{\text { NATURAL } \\
\text { RUBBER }}}{\text { HIGH-TECH }}$ IRON ORE & WOOD
\end{tabular}

DESIGN FOR THE DUMP

THE EU

RELIES ON

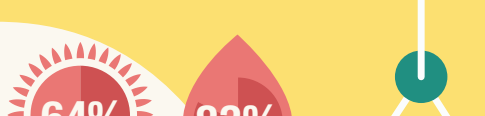

OON SOMPOLEN

Q.

(u)

(5) BY 2020:

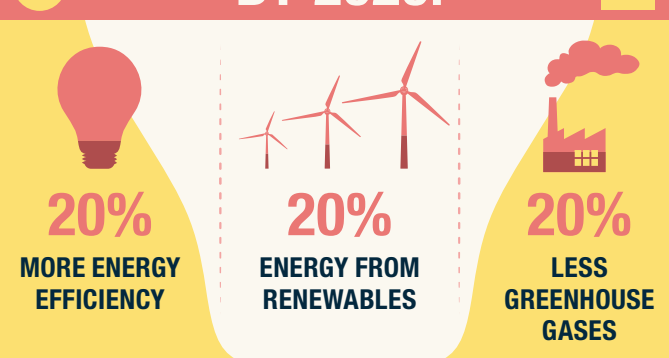

र्रे

SOLUTIONS? LOMGER

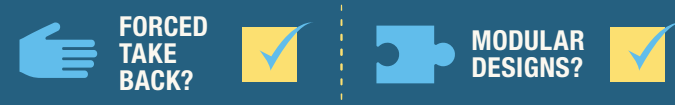
CRITICAL RAW MATERIALS

11

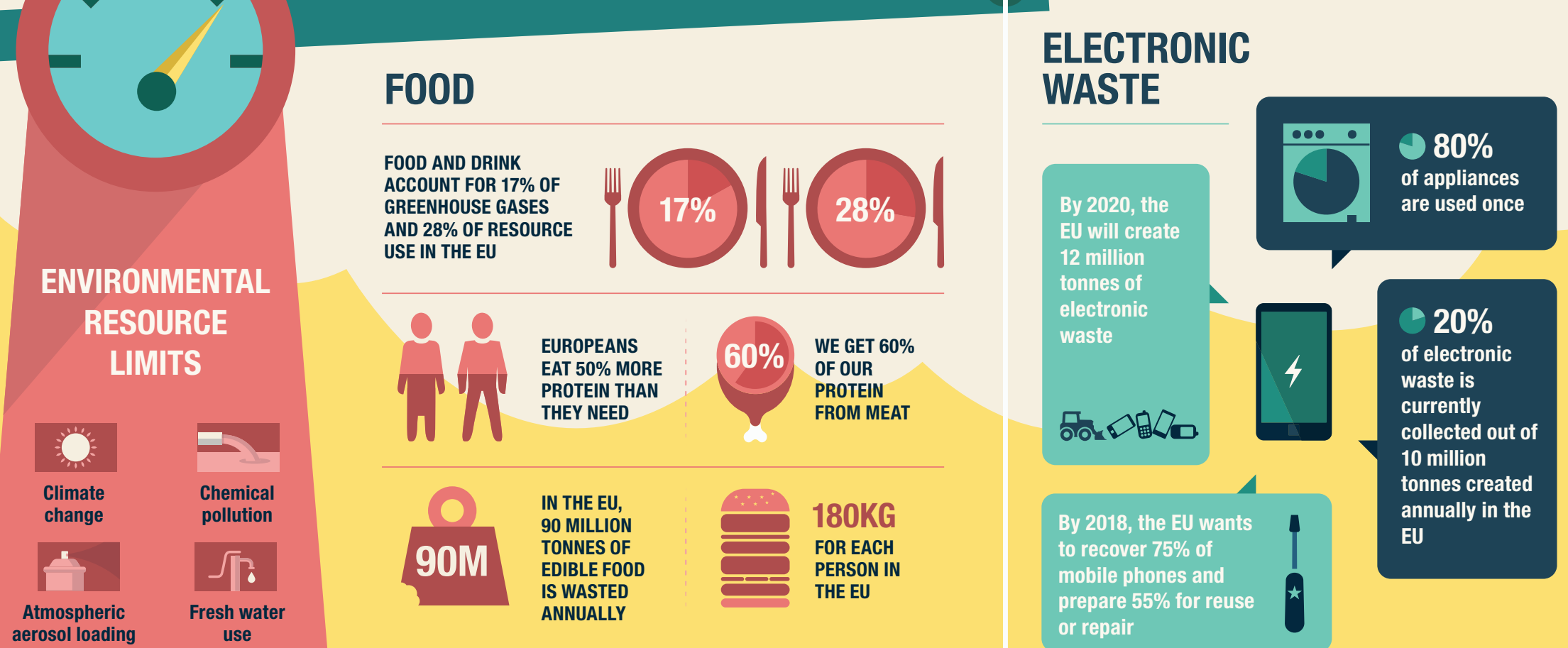

aresolithenty

Me

Ocean
acidification
Change in
land use

O

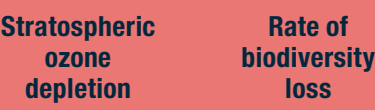

W $\mathrm{P}$

Interference with
nitrogenen and

nitrogen and
phosphorus cycles

WASTE: 3BN TONNES/ YEAR

\section{RESOURCES}

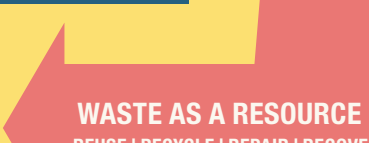

TRANSPORT

(1)

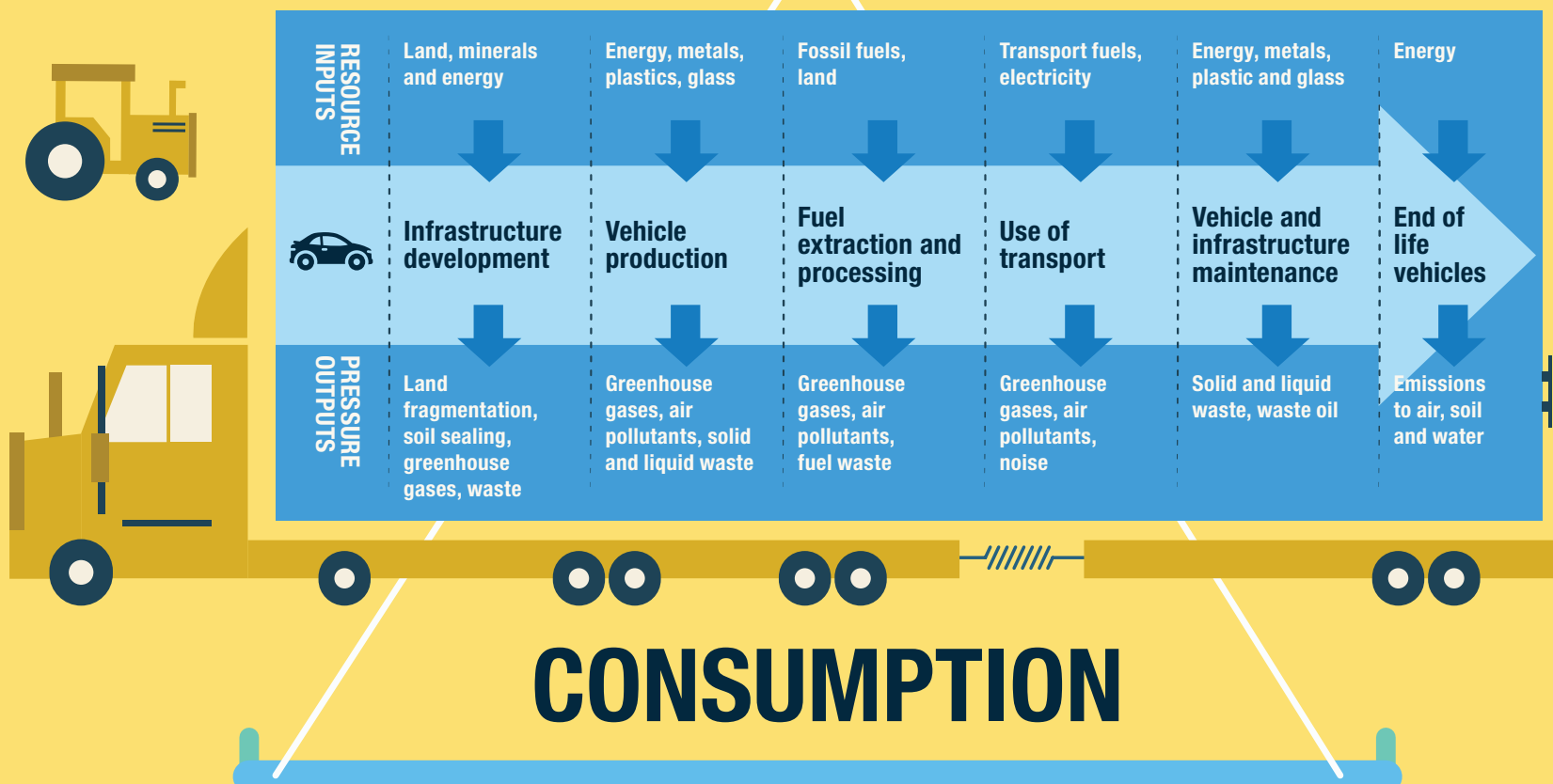

RELATIVE

CONSUMPTION

ECONOMIC

CONSIDERATIONS

TRIANGLE OF CHANGE
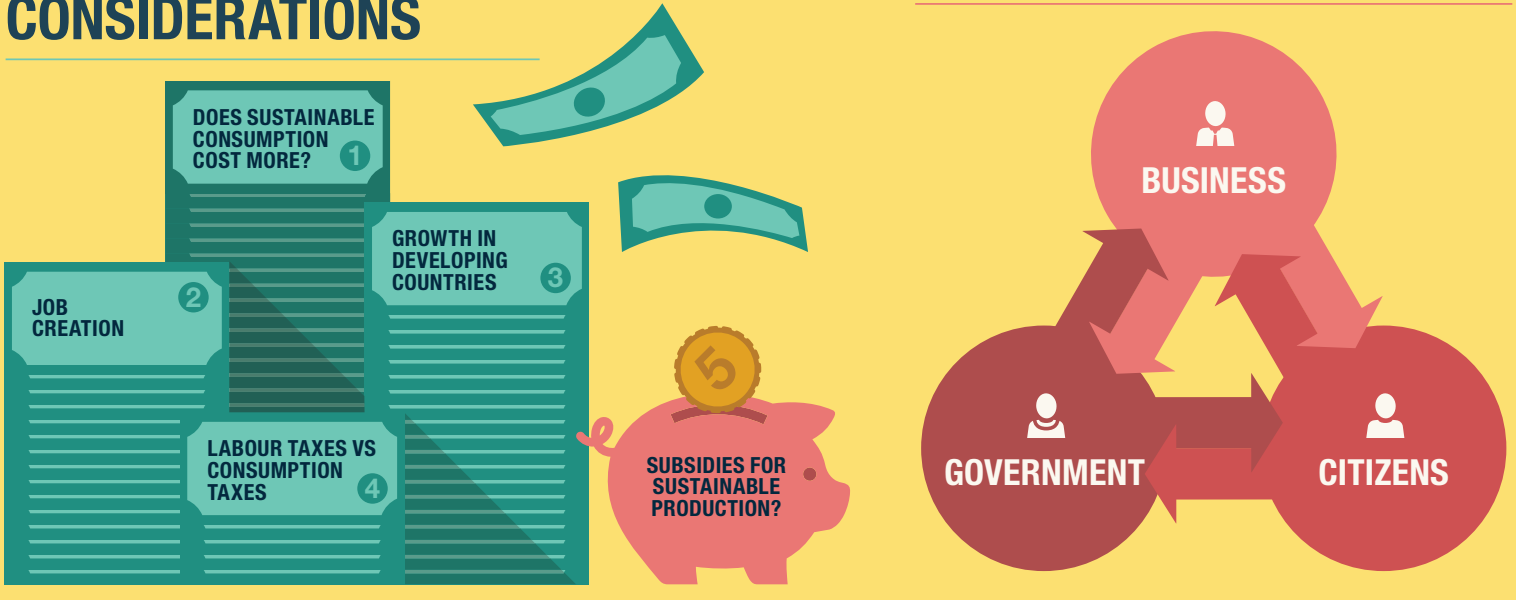

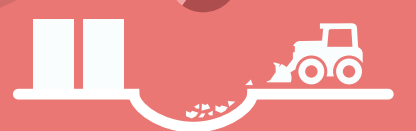

HAZARDOUS

WASTE

$90,000,000$

TONNES

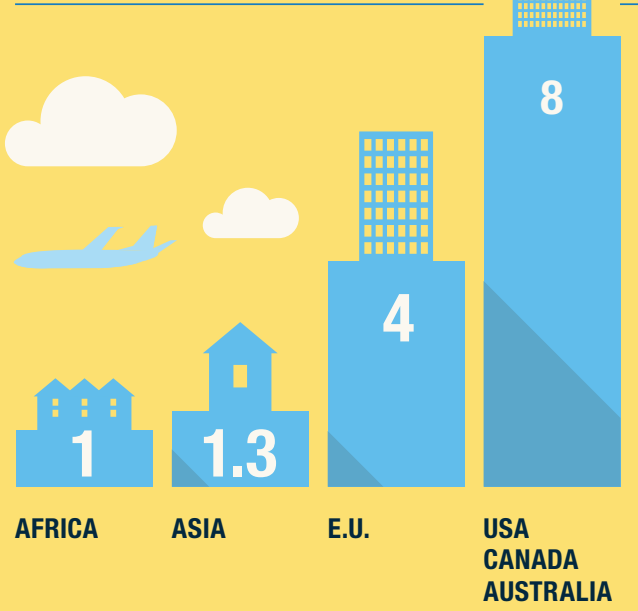

COLLABORATIVE CONSUMPTION

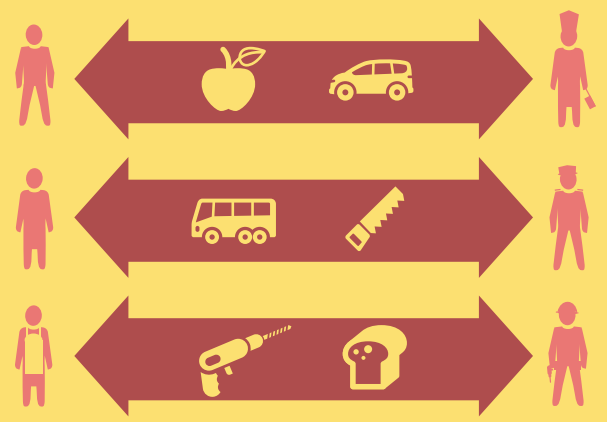
๑ 2014 DANISH BOARD OF TECHNOLLGY FOUNDATION, 


\section{REDUCING CONSUMPTION}

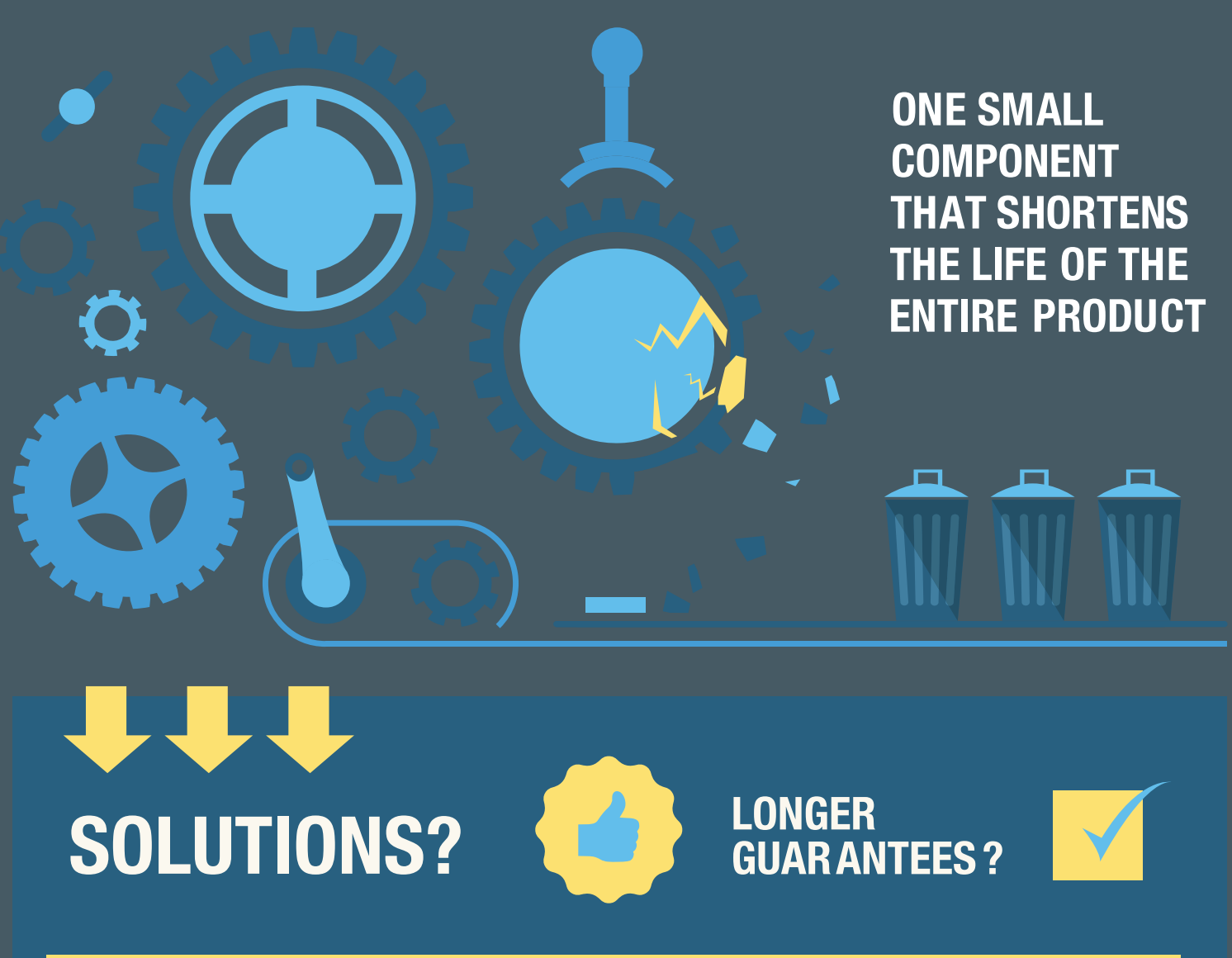

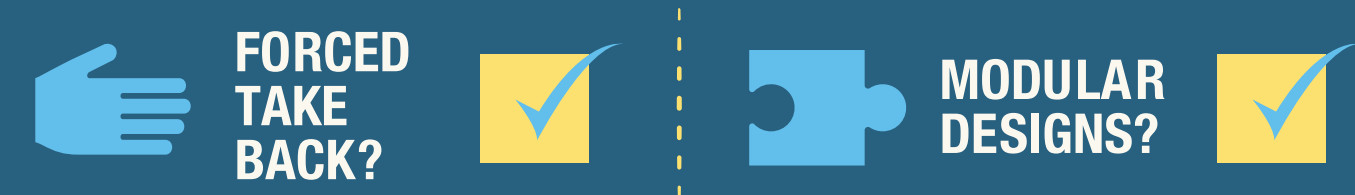

DESIGN FOR THE DUMP
IN THIS SECTION, WE'LL LOOK AT WHAT POLICYMAKERS CAN DO TO ENCOURAGE PEOPLE TO CONSUME LESS.

At present, many policy measures are aimed at reducing the impact of current consumption levels rather than at reducing consumption levels themselves. Therefore, there is scope for policymakers to consider measures to encourage behaviour that will cut consumption. The phasing out in the EU of energy-inefficient light bulbs and replacing them with more efficient ones is an example of how energy consumption can be lowered through policy making. ${ }^{15}$

Policies aimed purely at reducing consumption have, however, been questioned. Reduced consumption still places pressures on resources, society and the environment. And even if consumption levels dropped in developed countries, chances are that as developing nations grow their economies, overall global consumption would increase anyway. The concern is that even if developing nations adopted the most low-impact consumption patterns currently known, global consumption would still increase.

This has fuelled a debate in which some advocate an approach that decouples economic growth from a corresponding increase in the pressure

\section{on resources.}

Some go even further. They would like to see no growth in production or consumption (zero growth), or even a dialling back of current production and consumption levels (degrowth).

\section{CONSUMPTION INCREASES}

For now, though, consumption in the EU is on the rise. In part, this is because of our product choices.

Let's look at an example from the food sector. On average, EU citizens rely on meat for $60 \%$ of their protein intake. Yet meat requires huge amounts of input in terms of water, land and feed. The pressure meat places on resources is made worse by the fact that, on average, EU citizens eat about $50 \%$ more protein than they need. It has been estimated that if people in the EU halved their meat and dairy consumption, greenhouse gas emissions from agriculture would drop by $25 \%$ to $40 \%$. Nitrogen emissions would decrease by $40 \% .{ }^{16}$

Even where the environmental impact of individual products has been cut, the sheer

\begin{tabular}{l|l} 
Chapter 3 & 26
\end{tabular} 
RELATIVE CONSUMPTION

The average European citizen uses about $4 \mathrm{x}$ more resources than one in Africa and $3 \mathrm{x}$ more than one in Asia, but $1 / 2$ of one in the USA, Canada or Australia. ${ }^{19}$

While such broad averages hide nuances such as different consumption levels among countries on each continent, the numbers do provide a useful context. Not least when you think that the most potential for economic development is in Africa and Asia. Imagine if, in achieving EU living standards, these regions also reached EU consumption levels - or if everyone moved to US-style consumption. Could we manage to do so sustainably?

volume we consume them in may undo this reduction. This is called the rebound effect. Appliances are becoming more energy efficient, but we're using more of them and replacing them more often. Between 1998 and 2008, EU household spend on appliances rose almost $30 \%$. Moreover, $80 \%$ of the appliances we buy are used and then discarded rather than repaired or repurposed. ${ }^{17}$

In addition, the trend now is to build more and bigger houses for fewer people. Each home is equipped with modern appliances. That increases demand for gadgets, as well as for electricity.

Not only that. Each individual home needs to be heated or cooled at different times of the year. They need to be maintained. And the very construction of more homes consumes more resources.

Consumption has increased elsewhere too.

People buy more clothes and wear them for shorter periods of time. People like to keep up with fashions and trends. Not just in clothes, but

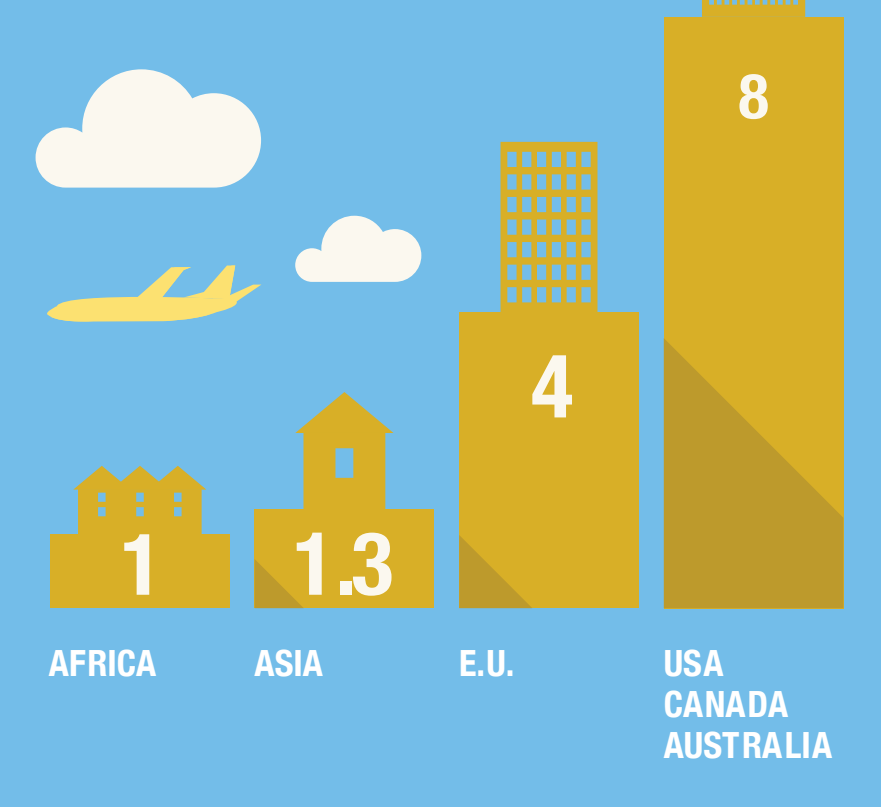

in electronic gadgets, cars, overseas holiday destinations - to name only a few.

As mentioned in the previous chapter, people move about more than ever before, mostly by car. They have greater freedom and independence of movement. When they travel as tourists, they have a significant impact on consumption patterns and resource depletion at their destinations. Increased mobility brings with it the consequence of increasing consumption elsewhere, not just at home.

Reversing these trends will require people to make significant changes. Some they will be happy to make of their own accord. Others may have to be directed by policymakers from above. In both cases, the big question is what (if any) changes would you be willing to accept?

\section{DESIGNED TO LAST}

Some of the current increase in consumption is accelerated by the relatively short lifespan of some products. A situation that is exacerbated by the fact that sometimes replacing a broken product is cheaper than having it repaired.

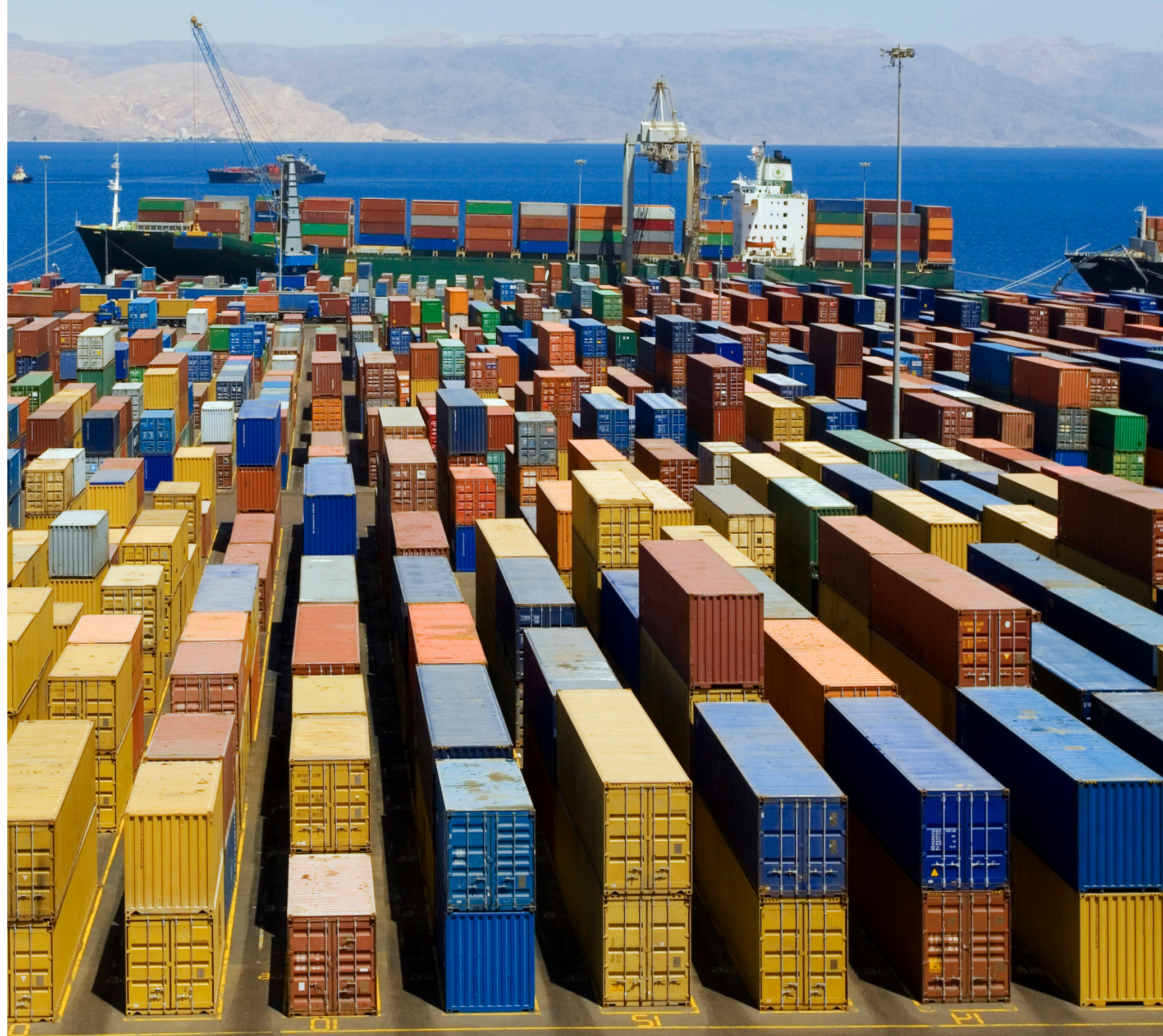

Chapter 3 । 28 


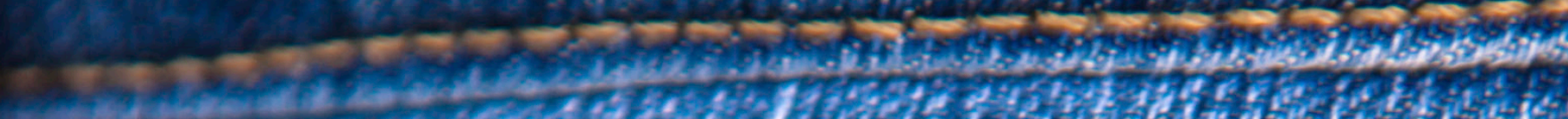

(n) 35iv

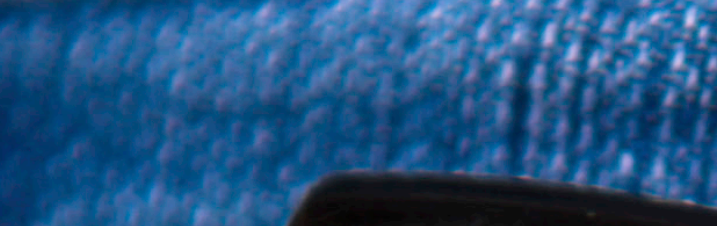
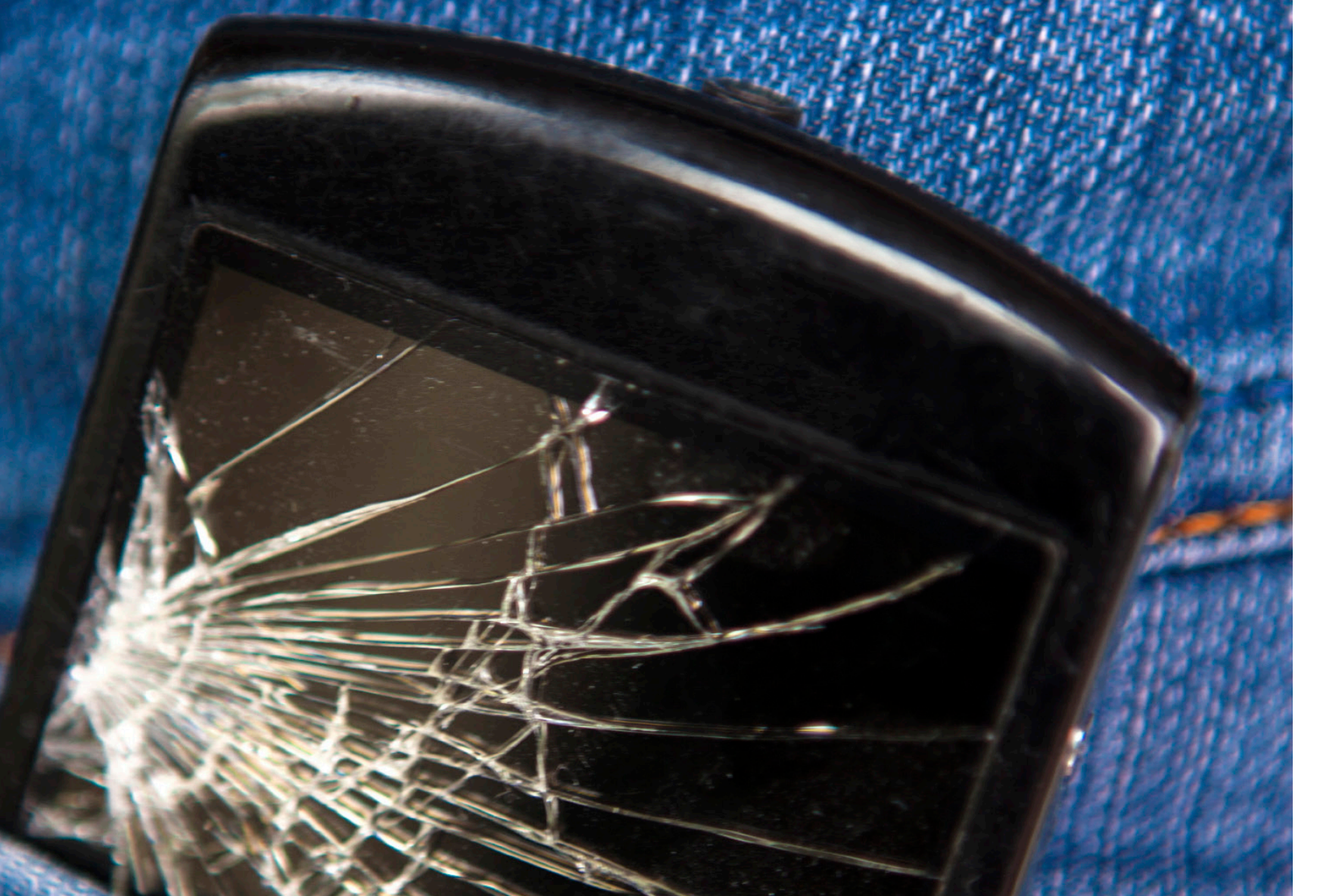
(1) cins cins

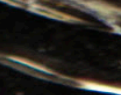
. vate a

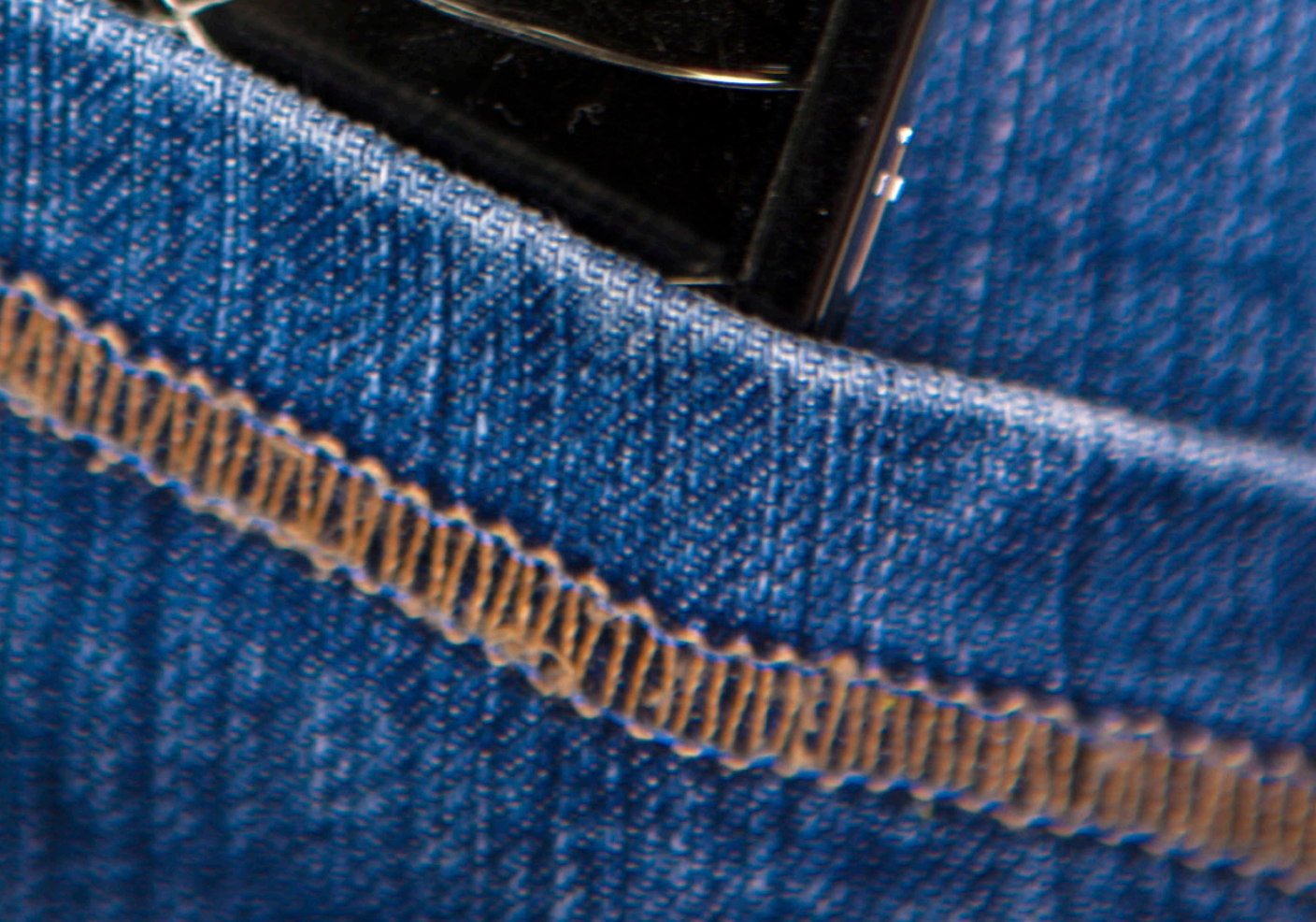

In some instances, technological advances mean a product has been overtaken by a quicker, more powerful, more useful or more effective alternative. Even though it still functions, replacing it has benefits.

It isn't unknown for products to be designed to fail after a period of time. Obsolescence is sometimes built in by manufacturers. In othe instances, advances in technology can make a product obsolete. Or consumers might feel an existing product is obsolete simply because a newer version has been released. That raises the possibility of looking at ways to increase the longevity of products.

Often, when a product does fail (or in the case of technology, become obsolete) the culprit is only a small component. That suggests that making products modular could increase their life span significantly by allowing easy replacement of the aged or broken part.

Alternatively, manufacturers could be obliged to take back broken products or design more durable ones in the first place.

Consumers, for their part, could refuse to buy short-lived products. Often, though, they are constrained by short-term financial limits. More durable products typically cost more, placing them outside the short-term spending power of some consumers. So even though higherquality products work out cheaper in the long run, some people cannot take advantage.

AUTHENTIC INFORMATION

Advertising is a powerful tool used by manufacturers and retailers to create a sense of aspiration. Buying the latest version of something is shown as enhancing the quality of people's lives.
Advertising is generally designed to encourage us to buy more from a particular company. That raises a key question about the role of advertising in sustainable consumption. Should regulators be looking at the relationship between advertising and consumption and sustainability?

One way in which a company can try to sway consumers to buy its products is to promote its green credentials. A product that reduces energy consumption can align with a desire among consumers to have a more cost-efficient product, or with a wish for a product that has a smaller environmental footprint.

When stressing the sustainability of a product or service, companies need to avoid greenwashing. This occurs when the image projected by a company doesn't align with the reality of its environmental and social policies.

Advertising isn't the only way in which manufacturers seek to get their message across to consumers. For instance, they also use public relations campaigns, social media programmes, labelling and standards.

Advertising, public relations and labelling can be used in initiatives to reduce consumption as well. A commonly cited example is the restriction on tobacco advertising in some countries, or health warnings on cigarette packaging. Measures need not be that far-reaching, though. Instead of outright bans, policymakers can ban campaigns that encourage consumption, such as twofor-the-price-of-one offers, or encourage buyone-now-get-one-free-later promotions. By the same token, they can stimulate campaigns that highlight sustainable products or environmental credentials. 


\section{TAXING DECISIONS}

Providing authentic and transparent information isn't merely an issue for those wanting to encourage more or less consumption. It drives to the very heart of how we price goods and services. A key question is, in a sustainable economy, what environmental, social and economic costs should be included in the prices of goods and services?

Broadly speaking, the prices we pay for products are a combination of:

1. what it costs the producer to make them, 2. what it costs the retailer to sell them, and 3. the additional value consumers are willing to pay.

However, there are costs that don't get wrapped up in traditional pricing. The costs to society are much higher. For instance, transporting goods adds pollution to the air. That poses a health risk. Who pays for the costs associated with respiratory problems? At the moment, such costs aren't reflected in the price label on the product associated with the pollution. Should they be? What costs would you like to see wrapped up in price tags?

One way to do this would be through consumption taxes. The European Commission has suggested that member states increase the use of consumption taxes such as sales taxes, energy taxes, special levies, excises and duties ${ }^{17}$. These taxes could be linked specifically to resource and material use. This could go hand in hand with a shift away from labour taxes. The effects of such a shift of taxation as a way of influencing behavior are still being researched and discussed.

One of the key concerns in relation to taxation is that it is fair for all. How should the tax burden be spread among citizens to avoid social inequality? Moreover, taxes are generally a politically sensitive topic. Particularly in countries where labour taxes and consumption taxes are already high, increasing the tax burden will pose additional political and socia challenges.

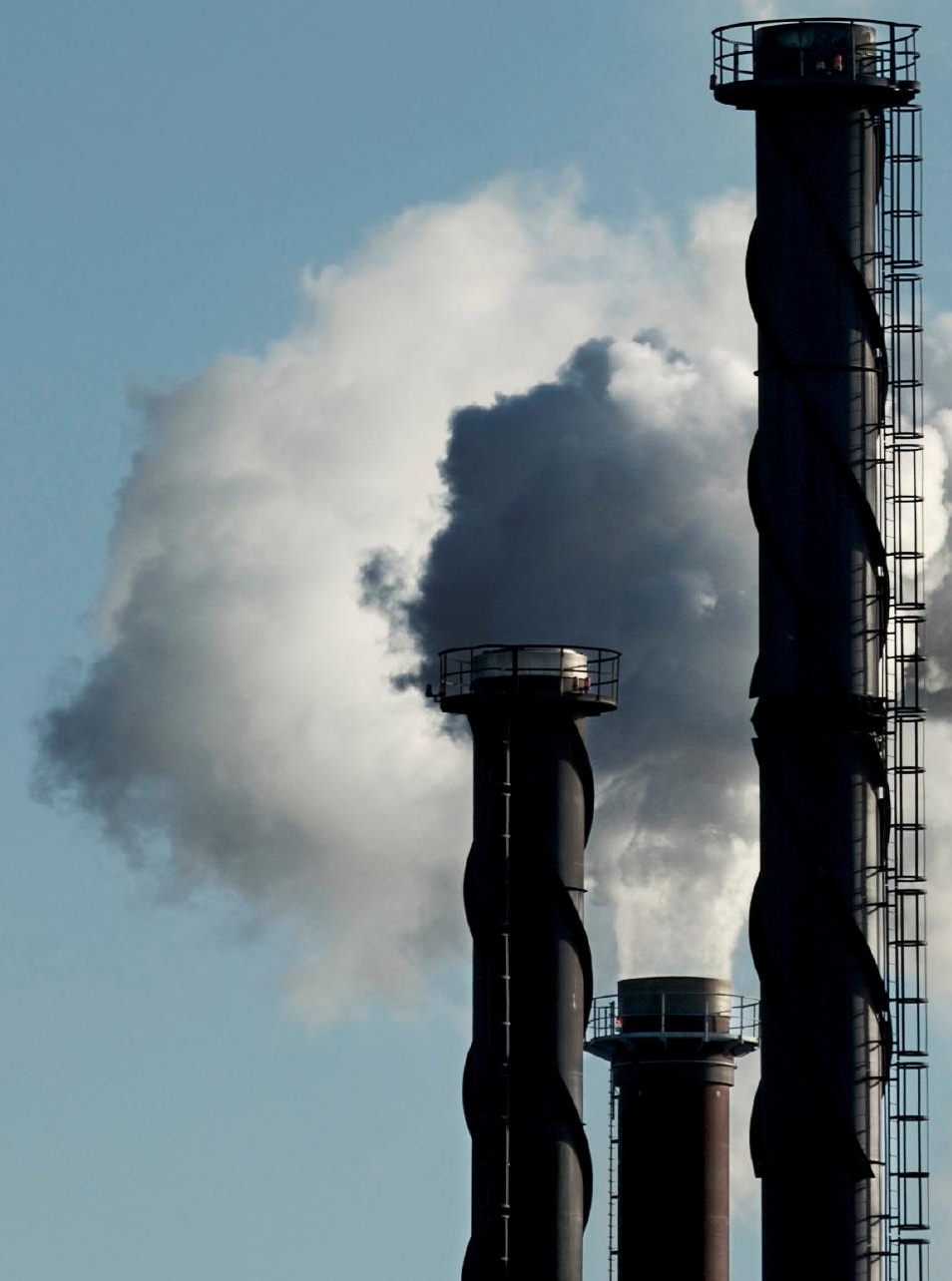




\section{REDUCING}

WASTE

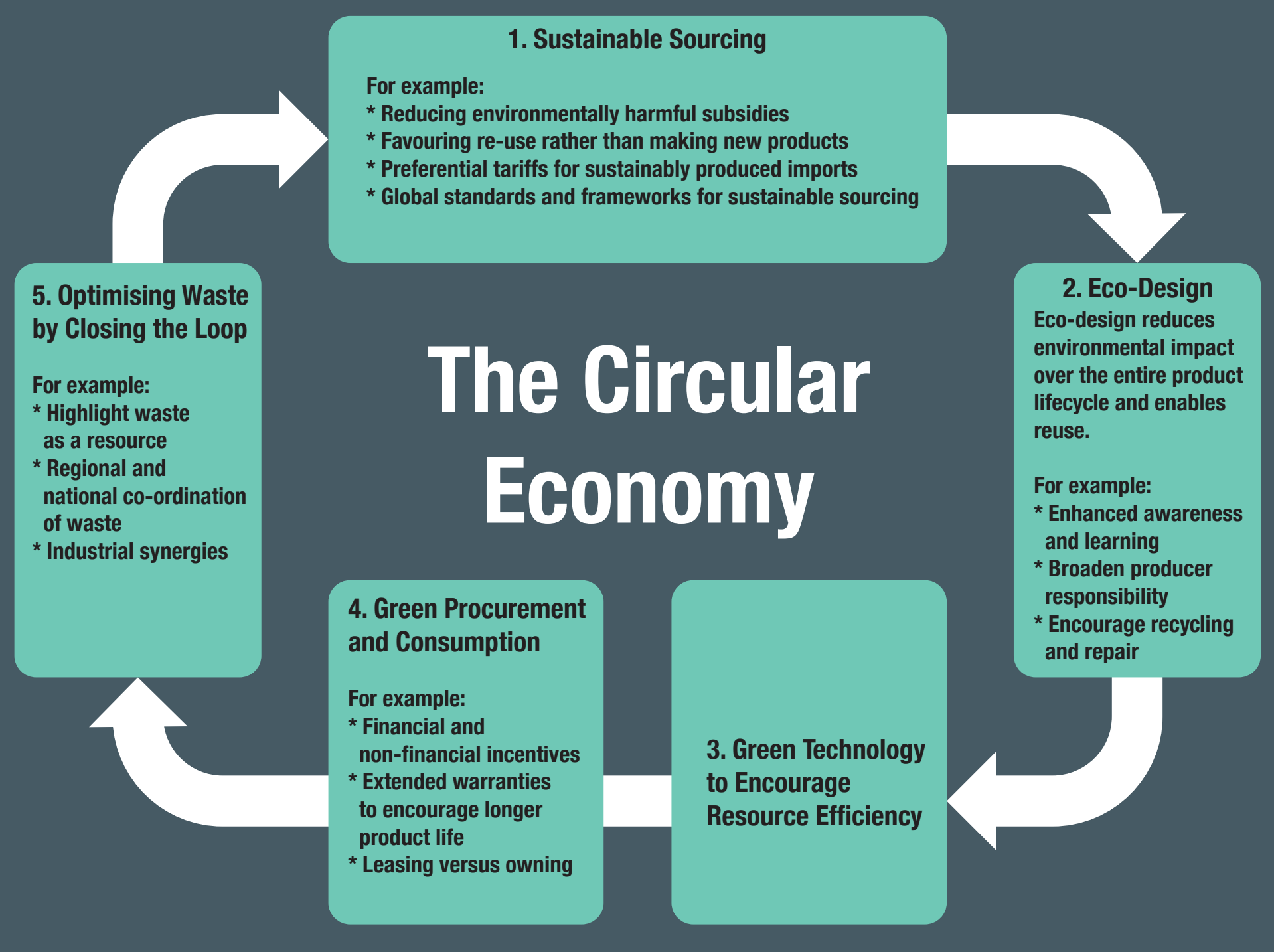

CONSUMPTION GENERATES WASTE, MUCH OF WHICH IS DESTROYED OR DUMPED. THIS ADDS ADDITIONAL PRESSURE ON RESOURCES, SOCIETY AND THE ENVIRONMENT. IN THIS SECTION, WE'LL DISCUSS WHAT COULD BE DONE TO CUT BACK ON WASTE.

Even though there have been successful moves to reduce the rate at which waste is being produced in EU member states, it remains a significant issue.

The EU creates 3 billion tonnes of waste each year. That is 6 tonnes of solid waste per head of the population. Around 90 million tonnes of the waste produced in the EU is hazardous ie, it is harmful to humans or the environment ${ }^{20}$. And by 2020, EU citizens will be producing an estimated $45 \%$ more waste than they were in 1995.

Around $60 \%$ of what people in the EU throw away ends up in incinerators or in landfill sites ${ }^{21}$. Neither is kind to the environment and both need careful monitoring. For instance, incinerators are subject to strict emissions limits.

How waste is managed differs from member state to member state. Some rely more on landfills than others. Some recycle and compost significantly more than others.

Municipal Waste Management for Selected EU States

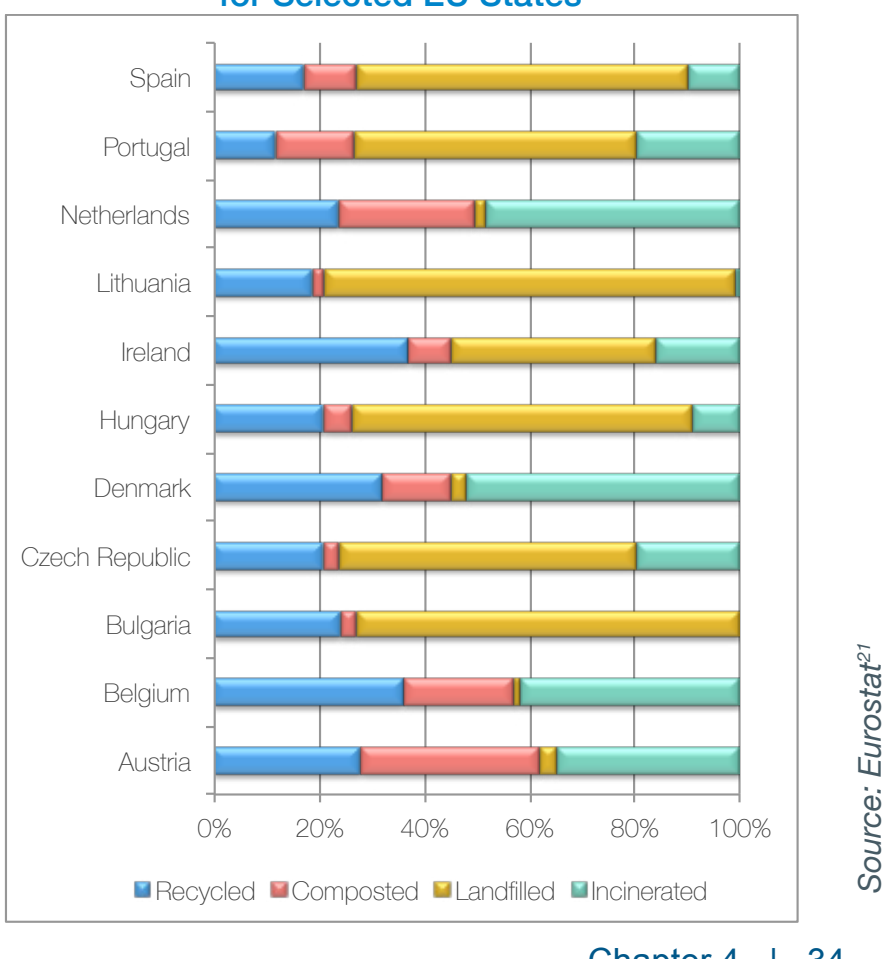

\begin{tabular}{l|l} 
Chapter 4 | 34 & 1
\end{tabular} 
While the amount of waste being produced in the EU has increased, so too has the amount that is being recycled or composted. The general approach across the EU is based on three principles: waste prevention, recycling and reuse, and improving the way we dispose of waste.

Each of these principles is reflected in the graph below.

The Five Steps of Waste Management

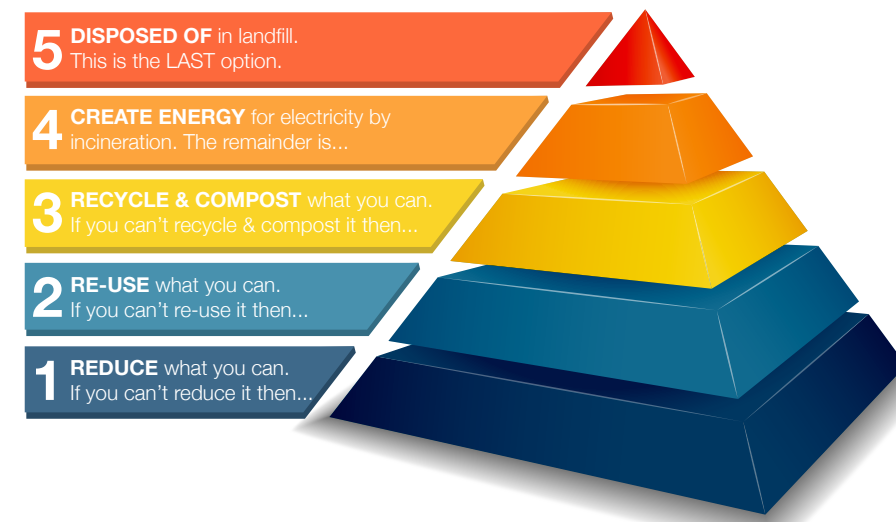

By tackling the issues raised at each step of waste management, societies can substantially decrease the waste they produce. However, there is a more ambitious end goal: an economy that produces hardly any waste, also referred to as a circular economy.

\section{CIRCULAR ECONOMY}

Industrial economies were founded on the notion that the earth's resources are infinite, or at the very least abundant and easy to get at. We've known for a while that this isn't the case. Many natural resources are finite. They will run out eventually if current consumption patterns aren't addressed.

In addition to resources becoming scarcer, the $\mathrm{EU}$ is facing increasing competition. Nations such as Brazil, Russia, India and China are looking to secure a bigger share of the global resources themselves as their economies grow. This poses an additional risk to the supply of these materials to the EU: we cannot guarantee that they will be available in the quantities we would like or at the time we need them.

To address these issues, the EU is keen to move towards a circular economy. It is one of the principles of its Europe 2020 strategy. Circular economies emphasize re-using, refurbishing and recycling, making them more resource efficient. A true circular economy produces zero waste. It does so partly by turning waste into a resource and partly by emphasizing processes that eliminate disposal and leakage of materials.

The benefits could be substantial. The European Commission estimates that an increase of 30\% in our resource efficiency could result in a GDP boost of 1\% across the EU by 2030 and create 2 million jobs ${ }^{22}$. However, such an increase would represent a significant leap compared with the current situation. It would require a huge amount of effort by policymakers, business and citizens alike to achieve it. Would the social and economic changes required be acceptable to everyone involved?

\section{FOOD WASTE}

Our consumption of food produces a significant amount of waste. Each year, we throw out 90 million tonnes of food waste in the EU. That's the equivalent of $180 \mathrm{~kg}$ per person. As much as one-third of this is still suitable for human consumption. ${ }^{23}$

Food waste is generated at every step of the food chain. Farmers, producers, retailers and consumers all contribute to the waste. In the $\mathrm{EU}, 40 \%$ of the waste occurs mostly at the retail and consumer level. ${ }^{24}$

In addition, our food consumption accounts for $17 \%$ of the greenhouse gases produced by the EU and $28 \%$ of the total amount of resources we use.

Tackling food waste would have a number of benefits. For instance, reducing food waste by $40 \%$ would reduce the amount of land used for food-related processes by almost $30,000 \mathrm{~km}$ sq. That's almost the size of Belgium. ${ }^{26}$

What, though, should policymakers be looking th to reduce food waste?

A lot of the food that is thrown out is either still edible or could be used in the production of other food products. While some countries in the EU already collect food waste separately, would there be scope to introduce a food collection scheme to capture still-edible food from retail outlets?

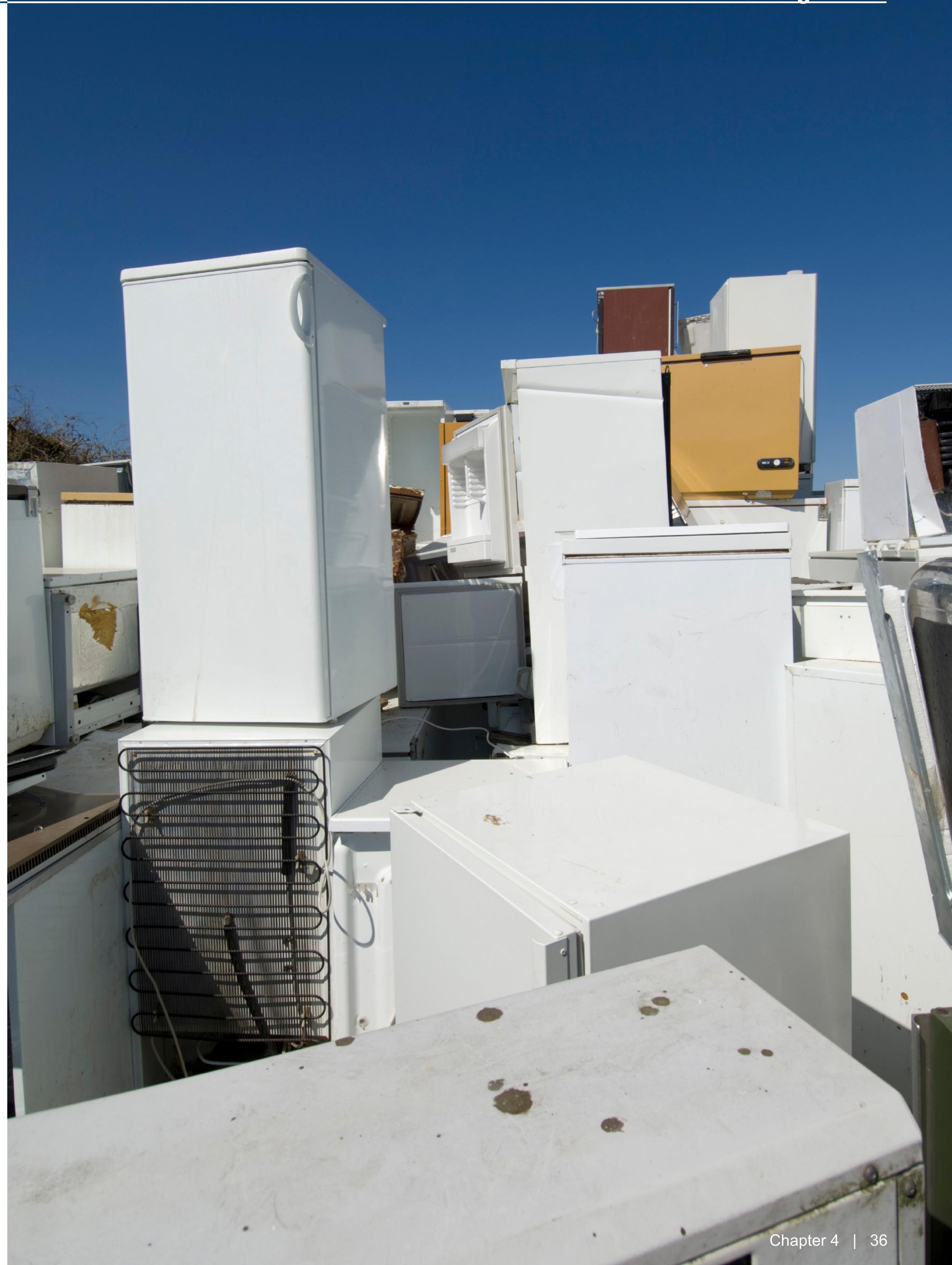


E-WASTE

The fastest growing category of waste in the EU is waste associated with electronic goods, such as smartphones, tablet computers, laptops, television sets, kitchen appliances and so on By 2020, the EU will produce an estimated 12 million tonnes of electronic waste each year. ${ }^{27}$

Looking at the use of mobile phones gives a good idea of the issues connected with electronic waste. Not only do many people have a mobile phone, they regularly replace their handsets, throwing away the older version. This would be less of an issue if recycling mobiles were easy. Unfortunately, it isn't. For a start, the small amounts of some minerals used in individual handsets make it hard to retrieve them. Also, mobile phones are complex products that are hard to separate. In many cases, obsolete phones are abandoned in drawers, cupboards and attics, taking them out of the recycling process altogether.

Even if unwanted mobile phones were easily retrievable, not all member states yet have a widespread electronic waste collection system or an infrastructure for recycling phones. This goes for other types of electronic waste as well. At the moment, the EU produces 10 million tonnes of electronic waste, only $20 \%$ of which it recovers. ${ }^{27}$

The EU has drawn up plans to increase this

figure. For instance, it aims to recover $75 \%$ of discarded mobile phones by 2018 and have $55 \%$ reused or recycled ${ }^{27}$. Raising the recovery rate of electronic waste will require manufacturers to make considerable economic and logistical changes. For example, they could think about modular designs and upgrades of their devices. At the same time, citizens would have to change their behavior too: fewer upgrades of electronic goods and participation in recycling programmes.

\section{CRITICAL MINERALS AND CONFLICT} MATERIALS

Mobile phones serve as a good example of an additional issue surrounding raw material consumption. Many of the key components used in the manufacture of mobile phones are sensitive. They fall into two categories: critical minerals and conflict materials.

Critical minerals are minerals that are vital to the EU's economies. Moreover, the supply of these minerals cannot be taken for granted. There are risks to the security of the supply chain that are mostly outside of the EU's control.

Conflict materials are materials that are mined in countries where the revenue they produce is used to fuel armed conflict. Current estimates suggest that natural resources are at the heart of $20 \%$ of the conflicts in the world today. ${ }^{33}$

\section{WHERE FOOD WASTE OCCURS}

Food is lost at numerous stages before it even reaches consumers, who may end up simply throwing it out anyway. Set out here is where and how food is lost along the way.

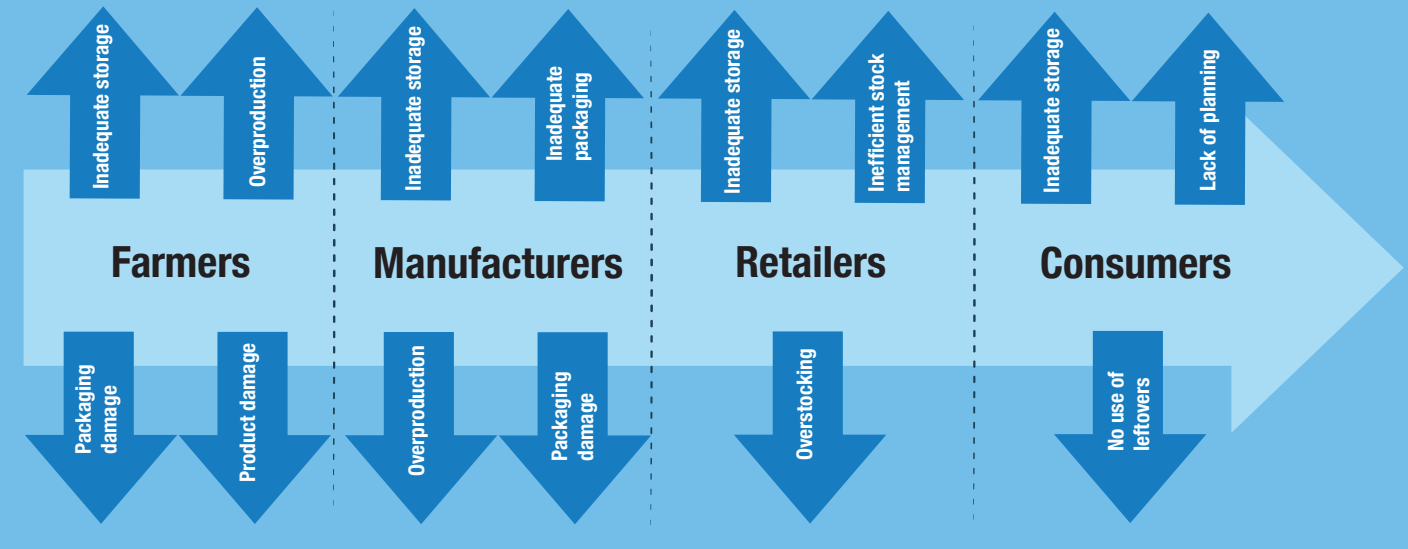




\section{THE EU'S DEPENDENCY ON IMPORTS}

Much of the EU's industry relies on imports for its raw material inputs. European industry currently imports $100 \%$ of the primary platinum, cobalt, rare earths and natural rubber it uses.

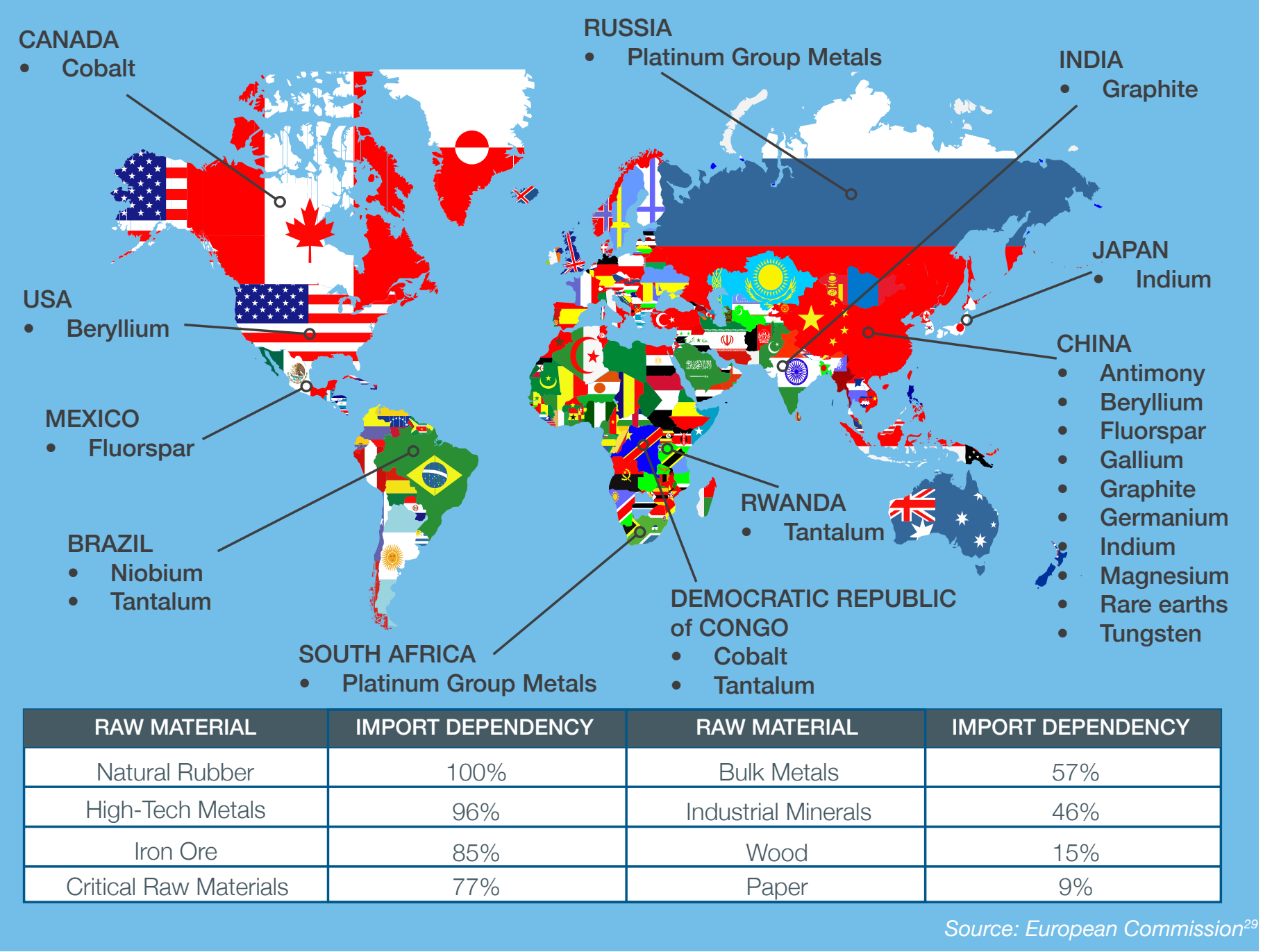

In the US, legislation is in place that will highlight companies that use minerals from the Democratic Republic of Congo and its neighbours. The intention is that increasing the transparency of where raw materials are sourced will reduce the use of minerals and the funding of factions associated with the violence in the region. ${ }^{28}$

The EU has been looking at two approaches recently. The European Commission favours a voluntary self-certification scheme for companies that wish to import minerals from non-conflict zones. The European Parliament would rather introduce binding legislation regarding the use of conflict materials that affects the entire product cycle from the mine to illegal movement of hazardous waste generated in the EU to poorer countries for disposal. Or they could require such shipments to go only to vetted companies with working practices that are safe both for humans and the environment.

On the production side, EU policymakers could impose a ban on the use of certain materials in goods. For instance, the EU introduced a ban on the use of lead solder in circuit boards in 2006. Such bans do impact consumer choice, however. The 2006 ban, for instance, resulted in certain goods, including some types of film camera, being taken off the market. ${ }^{30}$

Instead of bans, policymakers could consider financial incentives to encourage companies to adopt measures to reduce their use of hazardous, critical or conflict materials to begin with.

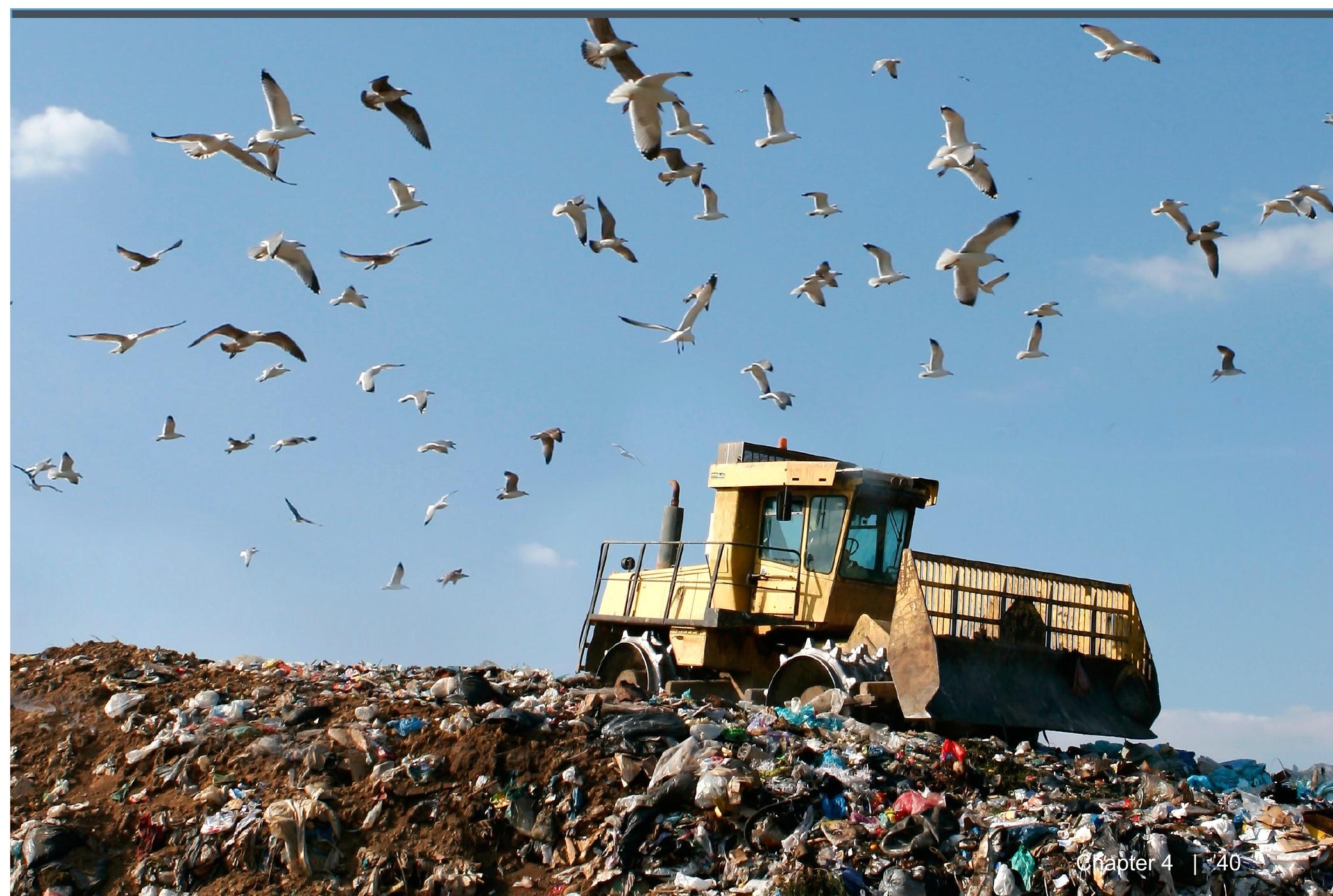


SPACE FOR YOUR OWN NOTES 


\section{APPENDIX}

(1) Wordd Commission on Environment and Development (1987). Our Common Future. Oxtord:
Oxtord University Press. p. 27 . ISBN O19828208X. (2) hitp://Mww:thwink.org//sustain/glossary/Sustanabaility.ht

(3) Willlile Fund 'Ling Planet' Report, 2008

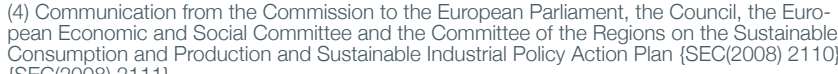

Europe 2020: hitp://ec. europa.e.eueurope2020/index_en.h.htm

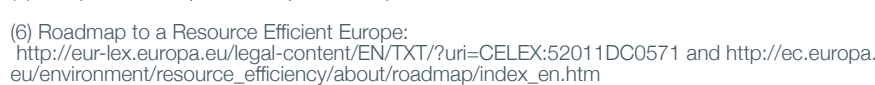

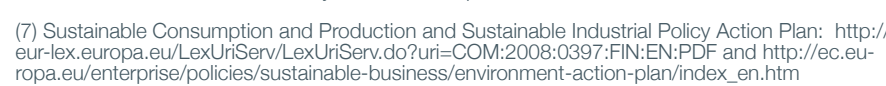

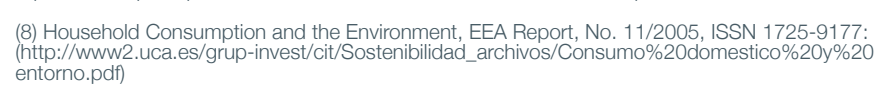
(9) Promoting Sustanabable Consumption, Good Practices in OECD Countries, OECD. 2008

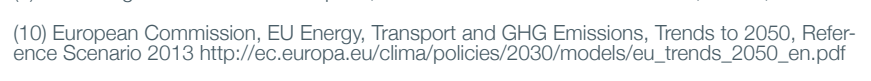

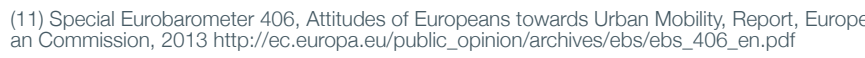

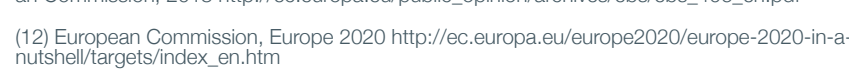

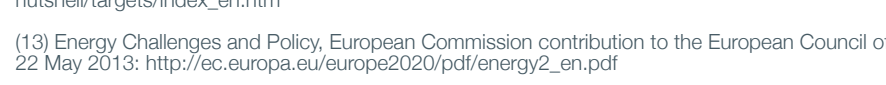

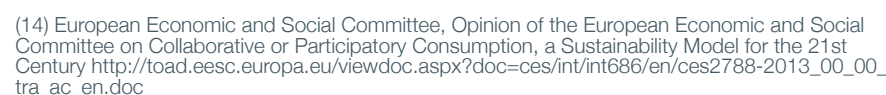

\section{(15) European
dex_en..hitm}

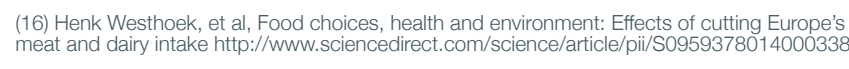

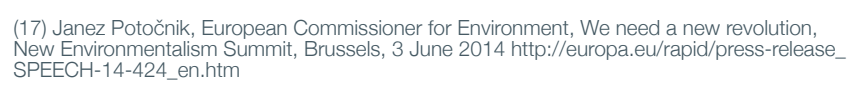

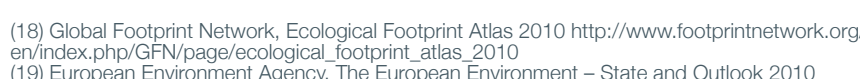

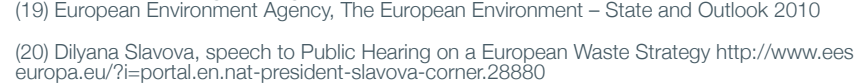

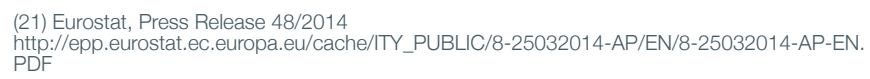

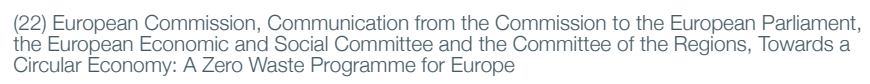
(23) European Commission http:///ece.europa.eufffood/food/sustainability/index_en.htm

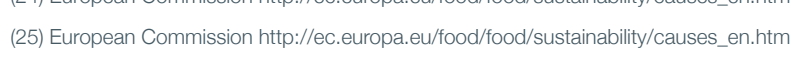

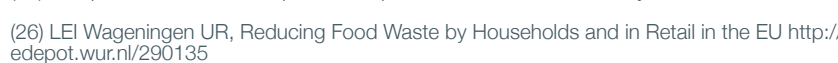
(27) European Commission hitp://ec. europa.e.eu/environment/waste/weee/index_en.htrm

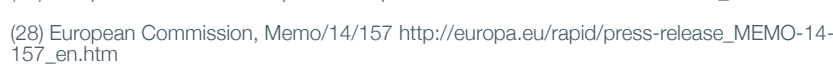

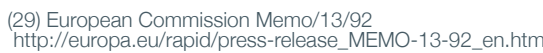

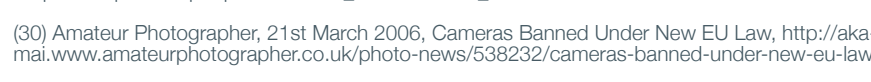

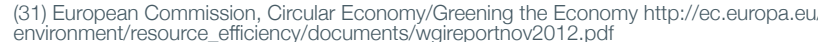

THE ORGANISERS OF EUROPE WIDE VIEWS ON SUSTAINABLE CONSUMPTION

\section{Y \\ PACITA}

The Europe Wide Views on Sustainable Consumption is part of the European research project Parliaments and Civil Society in Technology Assessment (PACITA). The citizen consultations are carried out in 11 countries across Europe by the following partners: Institute of Technology Assessment of the Austrian Academy of Sciences (Austria), University of Liège, SPIRAL (Belgium - Wallonia), the Applied Research and Communications Fund (Bulgaria), Technology Centre ASCR (Czech Republic), the Danish Board of Technology Foundation (Denmark), the Hungarian Academy of Sciences (Hungary), University College Cork (Ireland), Association Knowledge Economy Forum (Lithuania), the Rathenau Institute (the Netherlands), Instituto de Tecnologia Química e Biológica (Portugal), and the Catalan Foundation for Research and Innovation (Spain - Catalonia). www.pacitaproject.eu and citizenconsultation. pacitaproject.eu

\section{CREDITS}

\section{FONDEN TEKNOLOGI RÅDET}

\section{DANISH BOARD OF
TECHNOLOCY FOUNDATION}

Fonden Teknologiraadet - the Danish Board of Technology Foundation (DBT) (Denmark)

The Danish Board of Technology Foundation (DBT) is the parliamentary technology assessment institution of Denmark. It is an independent, non-profit private research foundation committed to deliberation, engagement and participatory processes in relation to the development of science and technology. The DBT specialises in technology assessment, applied social research and policy advice for decision-makers at the local, regional, national, European and global levels. The DBT is the Coordinator of the PACITA project and of the Europe Wide Views on Sustainable Consumption consultations. www.tekno.dk

\section{Université 18 \\ de Liège}

Université de Liège, SPIRAL - University of Liège, SPIRAL Research Centre (Belgium)

SPIRAL is a multi-disciplinary academic research centre within the University of Liège. It has a policy-oriented approach to risk analysis the interactions between science, technology and society; and public policies' evaluation. SPIRAL conducts its research and consultations at local, regional, national and international level. It works within four interrelated fields of research: science, technology and society; public policy; risk analysis; and participatory methods. www.spiral.ulg.ac.be

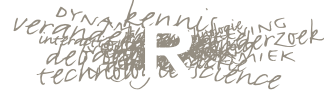

Rathenau Instituut - The Rathenau Institute (Netherlands)

The Rathenau Institute is an independen organization that encourages public and politica debate about the social, ethical and politica implications of science and technology. The institute also studies the organisation of the science system in the Netherlands and how it responds to scientific, societal and economic changes. Internationaly societal and econosic changes, In the the institute assesses technology for the Europea Parliament in the European Technology Assessment Group. www.rathenau.nl

\section{UCC}

Coláiste na hOllscoile Corcaigh - University College Cork (Ireland)

University College Cork is one of the leading research institutions in Ireland with just under 20,000 full-time undergraduate and postgraduate students. It delivers 120 degree and professional programmes through its 60 departments. The university's PACITA partner is the Financial Services Innovation Centre, which is a multi-disciplinary research centre in Ireland focused on financial services, services science and innovation. www.ucc.ie

\section{ifict||l||l}

Applied Research and Communications Fund (Bulgaria)

The Applied Research and Communications Fund (ARC) Fund is one of the most influential Bulgarian NGOs active in the fields of innovation and knowledge economy. Its activities encourage competitiveness and growth of economies in the region through promotion of innovation and transfer of advanced technologies and know-how. ARC Fund is also engaged in policy advisory work and cooperates closely with key government agencies and local authorities in Bulgaria in defining national, regional and sectoral research and innovation policies. www.arcfund.net

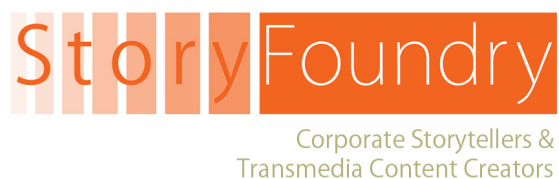

Story Foundry (Ireland)

This document's words, graphics and layout, as well as the accompanying videos were produced by Story Foundry, in collaboration with DBT and ULG, based on PACITA research. Story Foundry is a specialist corporate storytelling and content creation agency. It works with companies and organisations to help them create meaningful and engaging messages for highly targeted audiences. Story Foundry provides a full creative service and has expertise of full-funnel inbound marketing programmes, employer branding initiatives and information campaigns. Illustrations by Brian Wilson Design (Ireland), in collaboration with Story Foundry. www.storyfoundry.eu

LEGAL

The information in this document is provided as is and no guarantee or warranty is given that the information is fit for any particular purpose. The user thereof uses the information at its sole risk and liability. Neither the European Commission nor any person acting on behalf of the Commission is responsible for the use that might be made of the following information.

(c) PACITA and Story Foundry Ltd. 2014. Reproduction of the text is authorised provided the source is acknowledged.

All trademarks and copyrights are the property of their respective holders. 

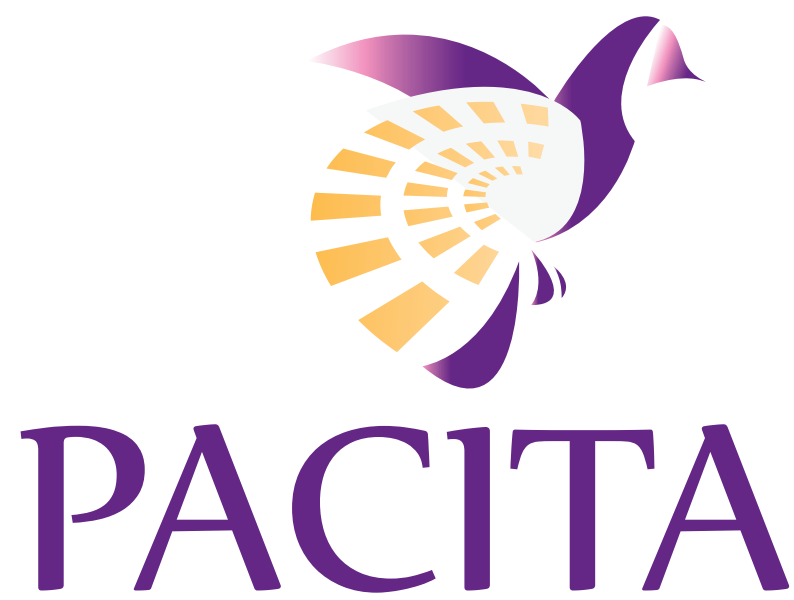

www.pacitaproject.eu 